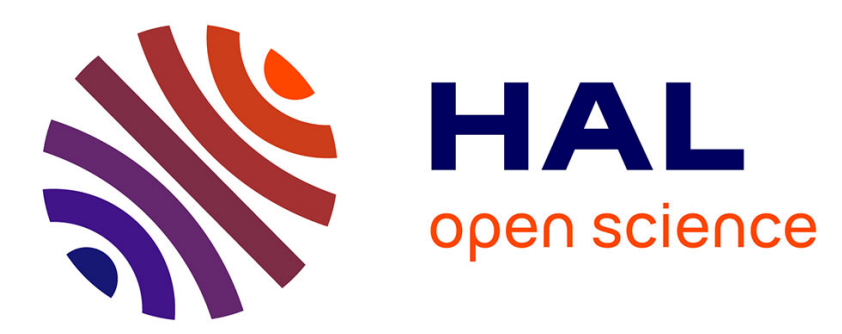

\title{
Computational exploration of metal-organic frameworks: examples of advances in crystal structure predictions and electronic structure tuning
}

\author{
Caroline Mellot-Draznieks
}

\section{- To cite this version:}

Caroline Mellot-Draznieks. Computational exploration of metal-organic frameworks: examples of advances in crystal structure predictions and electronic structure tuning. Molecular Simulation, 2015, 41 (16-17), pp.1422-1437. 10.1080/08927022.2015.1048511 . hal-01289190

\section{HAL Id: hal-01289190 \\ https: / hal.sorbonne-universite.fr/hal-01289190}

Submitted on 16 Mar 2016

HAL is a multi-disciplinary open access archive for the deposit and dissemination of scientific research documents, whether they are published or not. The documents may come from teaching and research institutions in France or abroad, or from public or private research centers.
L'archive ouverte pluridisciplinaire HAL, est destinée au dépôt et à la diffusion de documents scientifiques de niveau recherche, publiés ou non, émanant des établissements d'enseignement et de recherche français ou étrangers, des laboratoires publics ou privés. 
Computational exploration of Metal-Organic Frameworks: examples of advances in crystal structure predictions and electronic structure tuning

Caroline Mellot-Draznieks

Laboratoire de Chimie des Processus Biologiques, UMR 8229 CNRS, UPMC Univ Paris 06, Collège de France, 11 Place Marcelin Berthelot, 75231 Paris Cedex 05, France.

caroline.mellot-draznieks @ college-de-france.fr 


\title{
Computational exploration of Metal-Organic Frameworks: examples of advances in crystal structure predictions and electronic structure tuning
}

\author{
The purpose of this article is to consider some recent developments in the area of \\ the computational chemistry of metal-organic frameworks (MOFs), and more \\ specifically on their crystal structure prediction and electronic structures. We \\ intend here to illustrate how computational approaches might be powerful tool \\ for the discovery of new families of hybrid frameworks, helping to understand \\ their often complex energy landscapes. Also, metal-organic frameworks have \\ attracted a lot of attention due to their potential use for photocatalysis and \\ optoelectronic, making it necessary to develop strategies to control their \\ electronic structures. We will show how recent computational studies in this area \\ have allowed a better understanding of their electronic properties and their \\ potential tunability, highlighting when they have given successful guidelines for \\ the discovery of novel MOFs with targeted properties.
}

Keywords: metal-organic frameworks, ZIFs, energy landscape, optical band gaps, computational chemistry, QSPR, POMOFs, chiral MOFs

Crystal structure prediction (CSP) is indeed a distinct subfield from the much larger field of MOFs' computational chemistry, whereby CSP aims to genuinely predict existing crystal structures or produce new ones at the atomic level without the recourse to prior knowledge obtained from experiment. While CSP has a longstanding history in the field of molecular solids such as pharmaceuticals [1] and more recently molecular cage materials [2], a number of recent reviews have highlighted how CSP in the field of crystalline periodic solids is still relatively young due to methodological significant challenges $[3,4]$. Nevertheless, it has evolved dramatically over the last decade with major methodological developments as recently illustrated again in the area of inorganic solids [5]. This paper will attempt to present recent advances in the specific class of metal-organic 
frameworks. A first section describes various computational strategies developed so far for the genuine prediction of the crystal structure of MOFs, including building-block-based model building approaches and large-scale computational methods. A second section presents the use of CPS in the in silico design of new MOFs and their subsequent targeted synthetic trials, exemplified in the very active area of polyoxometalate metal-organic frameworks (POMOFs). A third section focuses on the exploration of the energy landscape of MOFs through the wellknown sub-family of Zeolitic Imidazolate Frameworks (ZIFs), and the less computationally explored field of chiral-linker containing MOFs. In a final section, we consider how the electronic structures of MOFs, namely their HOMOLUMOs, are key in understanding their properties, having in mind the rapidly developing area of MOF-based light-responsive photocatalysts and optoelectronic device. We will show that in this rather new field, DFT calculations, although applied to existing structures (rather than hypothetical ones), are readily used for the screening of MOFs, opening up opportunities for the computationally assisted fine-tuning of properties, such as light capture.

\section{CPS (Crystal Structure Prediction) of MOFs}

\section{1: General context}

What is meant by CSP in the much larger context of computational simulations of solids? The now-routine computational chemistry of solids, using force field methods or electronic structure calculations, may be used to identify the equilibrium structure of a predefined solid, starting from its experimental structure or an alternative approximate structural model. By contrast, "genuine" structure prediction involves a minimal amount of empirical knowledge leaving, for example, the atomic coordinates, the cell 
parameters, or the symmetry and space group undetermined, while fixing a target chemical composition. Genuine CSP should therefore result in a list of candidate periodic crystal structures or networks that are compatible with a list of predefined targeted features (of structural, topological or chemical nature), which might be further refined using either force field or electronic structure calculations.

A number of computational strategies for predicting crystal structures of periodic nets have been developed and reviewed $[3,4]$. They are capable of efficiently exploring the configurational space defined by the atoms or building blocks in a periodic cell, identifying the regions of interest, and quantifying the quality of the predicted crystal structures with respect to the predefined target features. Many methods rely on global optimization methods, such as simulated annealing (SA) [6], Monte Carlo basin hoping (MCBH) [7], and genetic algorithms (GAs) [8], which all involve a "cost function" over which minima are searched for. Another class of methods consists of topological enumeration, or tiling, used with great success in the prediction of zeolites $[9,10]$. The more recent metadynamics approach [11] allows the exploration of the Gibbs free energy as a function of the cell parameters by history-dependent dynamics to avoid already visited minima. Not all methods mentioned above have been used today to genuinely predict MOF periodic nets. Below, we will detail examples of strategies developed so far for the CSP of MOFs only.

\section{2: Building-block-based computational approaches}

The very first computational approach for predicting crystal structures of MOFs used the AASBU (automated assembly of secondary building unit) method [12]. Originally developed for inorganic framework solids $[12,13,14]$, it was extended to the structure prediction of MOFs in 2004 [15]. 
The key feature of the method lies in the combination of predefined buildingblocks and empirical "gluing" rules for assembling them at pre-defined "sticky" points. The exploration of their auto-assembly in 3D space uses a sequence of SA and energy minimization steps. The validity of the method was addressed with the simulation of existing prototypic solids, such as MIL-53, HKUST-1, and MOF-5 (Fig.1A). These structures were predicted using independent organic and inorganic units or a single large hybrid building-block like in the case of HKUST-1 (Fig.1B). One advantage of the AASBU method is its capacity to perform a topology-oriented search (corner-sharing versus edge-sharing assemblies, for instance) for crystal structures by assembling individual molecules, hybrid organic-inorganic building-blocks or even whole cages. It is therefore capable of highlighting topological relationships within groups of related materials, generating expected topologies together with new ones (Fig. 1C).

Related computational model building methods have then emerged that take advantage of predefined building-blocks $[16,17]$ to propose initial structural models of existing yet unsolved MOFs. The predicted structures are then suited for further Rietveld refinement of powder diffraction patterns. The most illustrative examples are the structure predictions of the very large cells of MIL-100 [18] and MIL-101 [19]. Through the preliminary listing of their possible constitutive building blocks, candidate structures were built. The correct models were identified by comparing their simulated X-ray powder diffraction patterns to the experimental ones. This revealed the structures of MIL-100 and MIL-101 as unusually large cells (over 370, $000 \AA^{3}$ and 700, $000 \AA^{3}$, respectively) and their models were directly used for their Rietveld structural refinement using synchrotron data. The occurrence of such an achievement remains exceptional, since prior knowledge of the constitutive building-blocks together with their connectivity mode is required. Still, these two MOFs structures remain the most 
illustrative case of a close interplay between the two fields of structure prediction and structure determination.

Wilmer et al. [20] have recently reported a large-scale screening and enumerative approach to generate more than 130,000 hypothetical MOFs using an original generation procedure from a given chemical library of building-blocks (based on the structures of known MOFs) and rapidly screen them to find the best candidates for methane adsorption. From a library of 102 building blocks (including 5 inorganic building blocks, 41 organic building-blocks, and 12 possible functional groups for the linkers), they generated 137,953 hypothetical MOFs and for each one calculated the pore size distribution, surface area, and methane storage capacity. The generation procedure creates hypothetical MOFs by recombining building blocks derived from crystallographic data of already synthesized MOFs such as MOF-5. Atoms are grouped into building blocks based on reagents used in the actual synthesis. Any building block can combine with any other building block, provided that the geometry and chemical composition local to the point of connection is the same as in crystallographically determined structures. Building blocks are combined stepwise, and when an atomic overlap occurs at a particular step, a different building block is chosen or a different connection site, until all possibilities are exhausted. By construction, this approach can generate a very large number of structures per second per CPU, and because it is enumerative, an entire portion of space of hypothetical MOFs can be systematically explored. Still, no attempt has been included in the work to predict which conformer is lower in energy, leaving the question of the viability and relative stabilities of the hypothetical MOFs generated open.

\section{3: Towards QSPR approaches}

There is a very large amount of literature exploring through simulations the 
adsorption/separation performances of MOFs, which will not be considered here, as a very large number of references and reviews may be consulted [21,22,23]. Despite the now-routine use of simulations for predicting gas adsorption isotherms and selectivities, we lack a generic tool for predicting the performances of existing or hypothetical MOF structures for a targeted application, probably because of the lack of general correlation principles. With MOFs, computational approaches are particularly adapted to evaluate the performances of hypothetical structures and explore the impact of topologies of linkers through computationally modified MOFs, yielding guidance on the potential interest of targeted topologies or ligands ahead of experimental trials.

Recently systematic and large-scale QSPR studies—directly inspired from the quantitative structure-activity relationship (QSAR) methods largely used in drug design — have appeared trying to correlate selected characteristics of computationally generated host-guest system represented by a series of descriptors with a target property.

Wilmer et al. successfully used the large-scale screening approach presented above to find structure-property relationships of MOFs for methane adsorption [20], $\mathrm{Xe} / \mathrm{Kr}$ [24] and $\mathrm{CO}_{2} / \mathrm{CH}_{4}$ and $\mathrm{CO}_{2} / \mathrm{N}_{2}$ separations [25]. Interestingly, their large-scale computational study revealed sharp correlations between structural/topology (e.g., pore size, surface area, and pore volume) and chemical features of MOFs, with absorbent evaluation criteria such as $\mathrm{CO}_{2}$ working capacity or $\mathrm{CO}_{2}$ uptake.

Nieto-Draghi et al. [26] studied a series of computationally functionalized ZIF-8 models for the enhancement of $\mathrm{CO}_{2}$ uptake. They highlighted that the dipole of the linker is the main criterion for enhanced affinity for $\mathrm{CO}_{\mathrm{s}}$. By virtually increasing the dipole moment from $0.3 \mathrm{D}$ up to $8.3 \mathrm{D}$ in the sodalite-type $\mathrm{ZIF}$, the authors find an exponential relationship between the ligand dipole moment and the computed isosteric 
heat of adsorption of $\mathrm{CO}_{2}$. In a further QSPR approach, the same authors compute the isosteric heat of adsorption of various polar and nonpolar $\left(\mathrm{Ar}, \mathrm{CH}_{4}, \mathrm{C}_{2} \mathrm{H}_{6}, \mathrm{~N}_{2}, \mathrm{O}_{2}, \mathrm{CO}_{2}\right.$, $\mathrm{H}_{2} \mathrm{~S}, \mathrm{SO}_{2}, \mathrm{H}_{2} \mathrm{O}, \mathrm{CH}_{3} \mathrm{CN}$ ) molecules in a large variety of functionalized sodalite-ZIFs structures [27]. The main descriptors include not only the dipolar and quadrupolar moments of the organic linker constitutive of each ZIF but also its pore mean curvature, the number of functional groups present on the linker, the dipolar moment of the adsorbed gas and its atmospheric boiling temperature. An equation is proposed able to predict the isosteric heat of adsorption for ZIFs with a simple mean of estimating the hydrophobic/hydrophilic nature of the ZIF.

In the same spirit, the derivation of QSAR models was used to identify the key factors that drive the caffeine uptake in a series of MIL-88 solids, such as the polarity, polarizability,and $\mathrm{H}$-donor capacity of the organic linker introducing variously hydrophilic and acidic functional groups $\left(-\mathrm{Br},-\mathrm{F},-\mathrm{CH}_{3},-\mathrm{NH}_{2},-\mathrm{NO}_{2},-\mathrm{OH}\right.$, $\left.-\mathrm{CF}_{3}\right)[28]$.

\section{In Silico Design of Polyoxometalate Organic Frameworks (POMOFs)}

\section{1: Context}

Polyoxometalates (POMs) consist of a large family of soluble anionic metal clusters of

d-block transition metals in high oxidation states $\left(\mathrm{W}^{\mathrm{VI}}, \mathrm{Mo}^{\mathrm{V}, \mathrm{VI}}, \mathrm{V}^{\mathrm{IV}, \mathrm{V}}\right)$ with a diversity of structures possessing magnetic, redox, and catalytic properties [29]. Besides their assembly into extended inorganic frameworks [30], POMs were only recently regarded as possible building-blocks for the design of POM-based MOFs, so-called POMOFs [31]. The combination of the extensive electrochemical activity and the diverse coordination modes in POMs, with the properties of MOFs, is obviously one attractive route toward the discovery of new multifunctional materials. This is motivated in 
particular by the creation of redox-active porous solids, provided that the electrochemical activity of POMs may be retained once incorporated in the insoluble MOFs. The current approach to produce POM-based MOFs is to consider the POM as an isolated inorganic building block, the inter-POM connectivity being achieved through a POM-M-L-M-POM scheme, where $\mathrm{M}$ is a transition metal and $\mathrm{L}$ is a multidendate organic linker, such as a dicarboxylate or a diphosphonate [32]. Although the number of hydrothermally synthesized POMOFs has continuously increased, the number of 3D frameworks is gradually increasing and those obtained by rational design strategy are rather scarce. Recent reviews are available that cover this rapidly developing area $[33,34]$. We intend to highlight in this section how simulations may play a role in this field in terms of structure prediction and understanding of energy landscapes.

\section{2: In Silico Design of Hypothetical POMOFs}

The general philosophy for synthesizing new extended MOFs has been the replacement of small building-blocks with larger ones, using the reticular chemistry concepts developed by Yaghi et al. [35]. Computationally, we may expect to be able to i) identify key features of particular topologies that may lend themselves to the design of POMOFs, ii) predict their crystal structures and minimize their lattice energies through geometry optimization so as to iii) identify viable candidates further amenable to synthetic trials.

Exploiting the analogy with zeolites (Fig. 2) and using a decoration strategy with the $\varepsilon^{-}$ Keggin and benzene-dicarboxylic acid as a bidendate linker, we showed that it was possible to construct a viable model of a hypothetical 3D POMOF possessing a tetrahedral zeotype net [36]. Willing to extend this initial work, our aim was to build a 
much larger number of hypothetical POMOFs possessing tetrahedral nets (typified by dense silica polymorphs and zeotypes) and explore computationally their energy landscape, with the ultimate goal of possibly synthesizing new structures. The motivation to explore tetrahedral nets of POMOFs was driven by the extraordinary corpus of available structures of zeolites, with over 180 unique zeotype topologies experimentally described [37]. This motivation was supported by the fact that a number of MOFs had already been synthesized with zeolite topologies, either fortuitously or rationally, as illustrated by the spectacular discovery of ZIFs [38].

Having the topology of zeolites in mind, the design strategy chosen above required the search for a suitable cationic POM, together with a suitable bidendate organic linker. For the POM, the authors turned to the recently developed family of compounds based on the $\varepsilon$-Keggin isomer of the reduced $\left\{\mathrm{PMo}_{12} \mathrm{O}_{40}\right\}$ anion [39] and chose its $\mathrm{Zn}(\mathrm{II})$ derivative, denoted by $\varepsilon$ - Zn, due to the likelihood of the external $\mathrm{Zn}$ coordination sites to adopt a tetrahedral arrangement and react with bifunctional linkers. Regarding the linker, we chose the rigid BDC to form the targeted POM-Zn-L-Zn-POM linkages, as BDC is a common linker in MOFs. With this combination, the $\mathrm{Zn}-\varepsilon$-Keggin cation possesses the ideal tetrahedral shape in which four $\mathrm{Zn}$ cations are exposed in a regular tetrahedral arrangement - in a similar fashion as oxygen atoms in $\mathrm{SiO}_{4}$ tetrahedra. Thus, it may replace the "Si" site in a parent $\mathrm{SiO}_{2}$ net, while the rigid anionic ligand may mimic the oxygen atom in the tetrahedral net. A selection of the 21 known uninodal (i.e., possessing one tetrahedral T site per asymmetric unit) hypothetical ZPOMOFs were constructed using a decoration strategy [40], that is, formally replacing the Si-O-Si links by POM-BDC-POM or POM-im-POM links using zeotypes from the IZA database (Fig. 3). This included protopytical zeotypes such as FAU, SOD, RHO, ABW, LTA or ACO. Also, dense structure types known as the most thermodynamically 
favoured silicates ( $\alpha$-quartz [QUA], cristobalite [CRI], and coesite [COE]) were constructed. In that purpose, the general code TOBUNPOROUS [41] was written to automatically (i) replace each $\mathrm{SiO}_{4}$ tetrahedron with an $\varepsilon$-Keggin building-block in the appropriate orientation, (ii) replace each bridging oxygen atom by a linker, and (iii) scale up the unit cell dimensions from a zeolite to a POMOF appropriately. Finally, further lattice energy minimizations used the generic uff force field plus rigid bodies on the $\varepsilon$-Keggin and the linker, while authorizing POM-linker (Metal-O) bond relaxation, yielding a final ranking of computed lattice energies of all hypothetical POMOFs as a function of their framework density (Fig. 4) [40].

As for silicates, the dense QUA-, CRI-, and COE-like Z-POMOFs were predicted as the most stable structures among all simulated ones. Yet, unlike silica polymorphs, it is not the QUA topology that is most stable but rather the CRI-like or diamond-like one. It is noteworthy that diamond-like MOFs have been reported as prevalent in terms of topologies (more than $70 \%$ of synthesized MOFs possess diamond-like nets), yielding credit to these predictions. Also, it is apparent that the most stable structures are those where the orbital overlap between the metal centres of the POM and the oxygen atoms of the carboxylic groups of the linker is maximized, making the crystal structures with the narrowest distribution of $\mathrm{Zn}-\mathrm{Zn}$ distances the most stable ones and reducing even further the range of acceptable POM- linker-POM connections to the CRI-, BTC-, and SOD-type Z-POMOFs. Remarkably, the simulations were followed by numerous synthesis attempts of POMOFs made of $\varepsilon$-Keggin and BDC, leading to the first Z-POMOF-1 structure, $\left[\mathrm{NBu}_{4}\right]_{3}\left[\mathrm{PMo}_{12} \mathrm{O}_{36}(\mathrm{OH})_{4} \mathrm{Zn}_{4}(\mathrm{BDC})_{2}\right] \cdot 2 \mathrm{H}_{2} \mathrm{O}$, which was found to possess the predicted most stable CRI topology, synthesized in a triply interpenetrated version, while exhibiting high electrocatalytic activity for the reduction of bromates [40]. Incidentally, this concurrence between the predicted most 
stable structure and the synthesized one suggests that a thermodynamic rather than kinetic control may be at play in Z-POMOF-1 synthesis. No other Z-POMOF has been synthesized to date; however, BTC and SOD appear as likely synthetic targets. Also, the geometry optimization of the interpenetrated structure Z-POMOF-1 provided a quantification of the net-net interactions $(\sim 7 \mathrm{kcal} / \mathrm{mol})$, indicating the added stabilization achieved through the formation of the more dense and interpenetrated structure.

We have also explored the possibility of using imidazolate as a potential linker in POMOFs (Fig. 5) [42]. The attempts to synthesize imidazole POMOFs materials, however, did not lead to 3D structures but rather to $2 \mathrm{D}$ or molecular structures so far $[42,43]$. Still, the new compound obtained with benzimidazole (bim), ie the $\varepsilon(\mathrm{bim})_{4}$ compound, was indeed promising in terms of rational design and synthesis since it possesses the targeted tetrahedral building-block required to propagate $3 \mathrm{D}$ structure.

\section{3: Possible role of the template in POMOFs}

Using 1,3,5-benzene as tricarboxylate linkers and tetrabutyl ammonium (TBA) as counterions in hydrothermal conditions, a series of novel Zn- $\varepsilon$-Keggin-based POMOFs possessing electrocatalytic efficiency for the hydrogen evolution reaction were synthesized [44]. It includes $\varepsilon(\text { trim })_{4 / 3}$, a new 3D open framework adopting a novel $(3,4)$-connected net, namely ofp, adopting the three letter code notation of the RCSR database [45]. At first, it was surprising that the "default" ctn- $(I-43 \mathrm{~d})$ and bor-like $(P-$ $43 \mathrm{~m})$ nets, already synthesized as covalent organic frameworks [46], are not the observed outcomes, although they possess more symmetric and simple topological features (one crystallographic tetrahedral T site and one crystallographic triangular site) than the observed opf net (I-42m, 2 tetrahedral sites, 1 triangular site). 
In order to understand the occurrence of the ofp topology rather than the ctn-and bor-like structures, force field-based calculations were used to evaluate the relative lattice energy of the ofp net in comparison with ctn- and bor-like polymorphs and find that the largest stability of the more complex ofp net is directly related to its greatest density (Fig. 6). In line with the previous study of Z-POMOF-1, the calculations in conjunction with the experimentally observed outcomes suggest that the successfully synthesized POMOFs so far were obtained under thermodynamic control. It was further considered that the absence of the default bor- and ctn-like topologies could point toward the key role of the TBA template molecules, in the absence of which no crystallization occurs. Docking of TBA molecules in the porous volume of $\varepsilon(\text { trim })_{4 / 3}$ was undertaken to locate the TBA molecules, the position of which could not be determined from single crystal diffraction. Four preferred sites for TBA were found, with in total 16 molecules located among the 18 ones of the as-synthesized $\varepsilon(\text { trim })_{4 / 3}$. The various strengths of TBA-POMOF interactions suggest that TBA molecules play either a structure directing role or a space-filling role, depending on their location in the channels. A subset of TBA molecules is found to occupy the centre of four-membered rings exhibiting the strongest short-range host-guest interactions among all docked TBA molecules, suggesting that they might stabilize the formation of four-membered rings of interconnected POMs.

\section{Computational exploration of the energy landscape of MOFs}

\section{1: Zeolitic Imidazolate Frameworks}

Zeolitic imidazolate frameworks (ZIF) delineate an important sub-class of low-density porous hybrid solids [47] with interesting thermal and chemical stabilities making them 
attractive candidates for gas sorption/separation, catalysis and sensing. The assembly of tetrahedrally coordinated cations with imidazolate linkers affords the formation of tunable and chemically versatile structures, including similar topologies to those of zeolites. Over 100 distinct frameworks with 25 different topologies, 16 linkers and a dozen of cations (including $\mathrm{Zn}^{2+}, \mathrm{Li}^{+}, \mathrm{B}^{3+}, \mathrm{Mn}^{2+}, \mathrm{Fe}^{2+}, \mathrm{Co}^{2+}, \mathrm{Cu}^{+}, \mathrm{Cd}^{2+}$ ) have been synthesized so far. The organic linkers are key parts of the ZIF scaffolds affecting their stability and preferred topologies [48] making the substituents of the imidazolate linker a key element of crystal engineering and of structure/properties relationships [49]. So far, linker-directed synthetic strategies of ZIFs have used the fact that the imidazolate linker is likely to play a structure directing role through linker-linker interactions, ranging from hydrogen bonding, $\pi-\pi$ interactions and steric hindrances. Such interactions have been empirically exploited to discover new topologies such as the LTA, SOD or RHO topologies through the judicious choice of bulky substituents or through the mixing of functionalized imidazolate [50,51].

Still, crystal engineering of ZIFs faces the current empirical challenge of the control of the topological outcomes, as a result of complex energy landscape. The latter has been rationalized a posteriori by examining the linker-linker interactions at play in the successfully crystallized compounds. The factors that determine which topologies will form as ZIFs and which will not have yet to be fully rationalized. We still lack a general method that provides a rationale between the targeted topology(ies) and the linker(s) to be used (which linker(s) for which topology and vice versa).

Following the initial DFT study by Leoni et al. [52], several computational dispersion-corrected DFT-D studies have explored ZIFs' energy landscape, including both Zn-based [53] and LiB-based [54] frameworks. It was established that a simple inverse relationship between framework density and lattice energies is at play in a 
similar fashion than in zeolites, recently confirmed by a thermochemical analysis study of MOFs [55]. Also, the dispersion interactions were shown to be an essential component in determining the energy landscape of MOFs [56]. The dispersioncorrected DFT-D calculations in ZIFs (performed on unsubstituted imidazolate-based structures) showed that the metastability of large pore ZIFs relative to the densest znitype ZIF is indeed due to their lower dispersion interactions. It is thus expected that dispersion will play an even more crucial role for bulkier when considering ZIFs with bulkier or more polarisable substituted imidazolates.

A recent QSPR and Non Covalent Interactions (NCI) analysis based on DFT-D calculations of methyl-substituted imidazolate-based (Li,B)-ZIFs was recently reported [57]. It shows that both the position and number of methyl- substituents on the imidazolate linkers have a profound impact on the energy landscape of ZIFs, reshuffling the ranking of stabilized versus less stable topologies that were otherwise almost isoenergetic with unsubstituted imidazolate. $\mathrm{NCI}$ analysis revealed that $\mathrm{CH}_{3}$ - groups induce repulsive interactions within the boron-centered cluster that are compensated by attractive non-bonded interactions at the larger scale of the solid (in green in Fig. 7). Besides the kinetic factors at play in ZIF synthesis which are difficult to consider from a modeling perspective, our calculations show that thermodynamic considerations are at work, explaining the intractability of certain topologies with certain linkers. These calculations provide insight into the magnitude of the thermodynamic penalties that must be overcome in order to form particular topologies and the energy scale that needs to be overcome to generate lower density materials - a target for many experimental groups. 


\section{2 : Chiral MOFs versus non chiral MOFs}

Chiral hybrid frameworks are of particular interest since they can readily be made from commercially available homochiral ligands and show promise in applications such as enantiomerically selective catalysis and separations [58]. Computational approaches provide valuable information about the relative stabilities of chiral and racemic hybrid frameworks.

Cheetham et al. studied the formation of a series of zinc 4-cyclohexene-1,2dicarboxylates, comparing the structures and stabilities of the cis- and trans-polymorphs [59]. Starting with the cis-1,2-dicarboxylate of 4-cyclohexene, the reaction with zinc salts at $60^{\circ} \mathrm{C}$ yields the cis-hydrate 1 , while at $180^{\circ} \mathrm{C}$ it yields first the anhydrous cisproduct 2 and then the trans-product 3. Using DFT calculations, it is found that the cisdihydrate $\mathbf{1}$ is more stable than the corresponding cis-anhydrous phase $\mathbf{2}$ and that the dehydration reaction is endothermic (Fig. 8), confirming that $\mathbf{1}$ is indeed more stable at lower temperature, as observed. Also, the trans-structure $\mathbf{3}$ is found to be more stable than the polymorphic cis-structure 2, consistent with its more dense structure, and suggesting that its formation is thermodynamically driven. Such thermodynamic control is in line with early experimental and computational studies of metal diphosphonates [60].

In a further study, the possibility of using $R, R$ - and $S, S$-enantiomers of trans-1,2dicarboxylate was also investigated, combining synthesis, calorimetry, and computational approaches [61]. The obtained racemic $R, R-S, S-$ and chiral $R, R-\mathrm{Zn}-$ dicarboxylates possess fundamentally different topologies (Fig. 9), the first being constructed from four rings and the second of three rings of tetrahedrally coordinated zinc ions. Using this time the force field developed for Zn-based MOFs by Allendorf et al. [62], we showed that the less dense racemic $R, R-S, S-\mathrm{Zn}$-dicarboxylate structure is 
more stable than the chiral $R, R$-dicarboxylate phase, in excellent agreement with the calorimetric estimations of differences of enthalpies of solution for both compounds. The relative stabilities of the racemic and chiral phases were further rationalized in terms of the subtle differences in the intra-layer energy of the component single layers and the non-bonded inter-layer interactions. On the one hand, the interlayer energy is stronger in the chiral $R, R$-structure than in the racemic $R, R-S, S$-structure. On the other hand, the intra-layer energy of the chiral structure exceeds that of the racemic one, yielding more favorable lattice energy for this structure despite its lower density.

On a larger scale, Cheetham et al. further studied the structurally diverse system of alkaline earth (Ca, Ba) [63] and Li [64] tartrates using L-, meso-, and D,L-tartaric acids. The relative energetic stabilities obtained by DFT calculations and calorimetric methods were again in excellent agreement, shedding light on the complex behaviour of these systems. Thermodynamic stabilities of the metal tartrate phases, together with kinetic factors such as ligand isomerization, are key factors controlling the phase behaviour.

\section{Electronic structures of MOFs}

Contrasting with the considerable research efforts dedicated to adsorption/separation and catalysis applications for MOFs, the research effort focusing on the potential use of MOFs into electronic devices is comparatively more recent $[65,66,67]$. MOFs have been identified as wonderful platforms for designing new solids potentially interesting for solar energy harvesting and photocatalysis [68]. Such interests make it necessary to develop strategies to control their electronic structure. Excellent recent reviews are available on the rapidly developing area of MOF-based light-responsive photocatalysts and optoelectronic devices [69-72]. In remarkable contrast to traditional photocatalysts, the electronic structure of MOFs may be tuned through the modification of the organic 
linker or metal centres, thus opening avenues for the control at a molecular level of their chemical and physical properties as photocatalysts.

In that respect, electronic structure calculations are seen as valuable routes to investigate the properties of redox- and photo-active frameworks. They are particularly suited to study independently the two parts, ie the inorganic and organic subnetworks, which might be tailored to alter the electronic structure of a MOF. Still, DFT-calculated band gaps are smaller than the experimental ones, in line with the acknowledged fact that DFT usually underestimates the band gaps (which may be partially corrected by the use of DFT+U method, hybrid functionals such as B3LYP or HSE06). Although accurate calculations of MOFs' electronic structures remain challenging, in particular due to their often very large crystallographic unit cells, computational methods are essential to estimate trends in series of structurally or chemically related MOFs and understand the fundamentals of their physical properties.

Following the early work by Dovesi et al. [73] the electronic behaviour of the archetypal MOF-5 has been both experimentally and computationally investigated [67, 74-76]. It is acknowledged that the conjugated aromatic ring is responsible for the energy transfer to the inorganic subunit, here $\mathrm{Zn}_{4} \mathrm{O}_{13}$, which is driven by the energy differences between the highest occupied molecular orbitals (HOMOs) and lowest unoccupied molecular orbitals (LUMOs) of the linker. Maintaining the parent cubic topology of IRMOF-1 emanating from its $\left(\mathrm{OZn}_{4}\right)^{6+}$ tetrahedral building blocks, the impact of a wide range of poly-aromatic organic linkers on the electronic properties were calculated [74]. The HOMO-LUMO energy difference is dominated by the $\mathrm{C} \mathrm{sp}^{2}$ states of the organic linker, with optical band gaps between $1.0 \mathrm{eV}$ and $5.5 \mathrm{eV}$, predicting that longer linkers might offer narrower band gaps. Further experimental studies on a number of these linkers have later confirmed these early predictions [75]. 
More recently, the electronic band structures of a series of isoreticular IRMOFs was investigated, focussing in the impact of aromatic versus antiaromatic linkers or the impact of halogen atoms $(\mathrm{F}, \mathrm{Cl}, \mathrm{Br}, \mathrm{I})$ substituents on the parent benzene-dicarboxylic linker [77]. They provide a detailed interpretation of their results and possible guidelines for synthetic trials. One important conclusion of the work is that the tunability of the band gap depends again essentially on the chemical bonding of the organic linker, thus identifying iodine as the best candidate for a reduced energy gap and higher valence band maximum in the case of the bdc linker.

Turning to the impact of the metal clusters on MOFs' electronic structure, Cabrera et al. theoretically explored in an early study the impact of the nature of the transition metal in IRMOF-1, concluding that it remains unchanged upon replacement of $\mathrm{Zn}$ with $\mathrm{Be}, \mathrm{Mg}, \mathrm{Ca}$, and $\mathrm{Cd}$ [78]. By contrast, varying virtually the zinc-to-cobalt ion substitution ratio in the same Zn-based IRMOF-1 structure, band gaps ranging from semiconducting to metallic states could be achieved [79]. Alternatively, by comparing the computed HOMO-LUMOs of three existing MOFs that contain the same bdc ligands (namely, IRMOF-9, Zn5-BPDC, and CPO-7), Liu et al. concluded that increasing the size of the Zn-based metal cluster leads to a systematic red shift in optical band gaps [80]. It has been predicted through a computational study that the band gap of the parent MOF-5 $(\sim 3.5 \mathrm{eV})$ could be modified to absorb visible light by substituting the oxygen anion of the metal oxide core $\mathrm{ZnO}_{4}$, with sulphur anions $\left(\mathrm{Zn}_{4} \mathrm{~S}: 3.30 \mathrm{eV}\right)$ or selenium anions $\left(\mathrm{Zn}_{4} \mathrm{Se}: 2.91 \mathrm{eV}\right)$ that allow a shift of the Fermi level due to their electron-rich properties [81]. The tunability of MOF-5 electronic structures was further computationally explored by using a systematic crossed combination of different metal (X) and anion (Y) atoms (i.e., $\mathrm{X}_{4} \mathrm{Y}-\mathrm{MOF}-5$ where $\mathrm{X}=\mathrm{Zn}, \mathrm{Cd}, \mathrm{Be}, \mathrm{Mg}, \mathrm{Ca}, \mathrm{Sr}, \mathrm{Ba}$ and 
$\mathrm{Y}=\mathrm{O}, \mathrm{S}, \mathrm{Se}, \mathrm{Te})$, the virtual materials possessing optical band gaps ranging from $1.7 \mathrm{eV}$ to $3.6 \mathrm{eV}$ assigned to the electronic state of the chalcogen atoms [82].

It is worth commenting here that MOFs were referred early on, rather incorrectly, to as semiconductors, implying similarities with their inorganic counterparts. In the latter, semiconductivity results from delocalized valence and a conduction band though which charge transport occurs. It has now acknowledged that MOFs such as those considered above are indeed different from classical inorganic semiconductors and should be considered as periodic arrays of self-assembled molecules retaining their individual discrete absorption feature. Turning again to MOF5 for example, the calculated electronic structure is indeed consistent with localized charge carriers and low levels of conductivity [83]. Overall, there is now a consensus that HOMO-LUMO (MO: molecular orbitals) or HOCO-LUCO (crystal orbitals) terminology is more adapted to describe the electronic structure of non-conducting MOFs, although the "band gap" terminology is still largely used.

Importantly, a general approach was recently proposed by Walsh et al. to allow the alignment, and therefore comparison, of the electronic levels of six prototype materials (MOF-5, CPO-27-Mg and HKUST-1, COF-1M, ZIF-8, MIL-125) [84]. In essence, the vacuum level of porous metal-organic frameworks is determined by taking the electrostatic potential at the center of the pore as a reference (Fig. 10A). The electron removal energies, i.e. ionization potentials, for the six archetypal MOFs are reported, thus allowing the relative positioning of their electronic levels, although they belong to chemically and structurally different families of solids (Fig. 10B). This is worth highlighting here that this kind of alignment might be useful for evaluating MOFs and their potential use for photocatalytical reactions, allowing to compare their electron affinity to experimental redox potentials. 
The synthesis of a new class of zirconium-based MOF materials based on the recurrent $\mathrm{Zr}_{6} \mathrm{O}_{4}(\mathrm{OH})_{4}\left(\mathrm{CO}_{2}\right)_{12}$ building block, has early on attracted a lot of attention [85] due in particular to their very high thermal stability and surface areas. Interestingly, Silva et al. [86] reported the photocatalytic hydrogen generation in water/methanol using $\mathrm{UiO}-66$ and the aminated $\mathrm{UiO}-66-\mathrm{NH}_{2}$ as visible-light photocatalysts, making the understanding of the electronic structure of this family of compound needed. A detailed combined experimental and theoretical study of UiO-66 (based on $\mathrm{Zr}_{6} \mathrm{O}_{4}(\mathrm{OH})_{4}$ clusters and terephtalate) MOF was also reported [87]. It is shown that in both hydroxylated and dehydroxylated structures, the carbon atoms of the organic linker are those involved in the modulation of the HOMO-LUMO, while $\mathrm{Zr}$ atoms do not play any role, while pinpointing different behaviours between UiO-66 and MOF-5 with respect to those of their corresponding oxides, $\mathrm{ZrO}_{2}$ and $\mathrm{ZnO}$. Recent detailed computational studies explored the complete series of $\mathrm{UiO}-66,-67$ and -68 with various metal centres $(\mathrm{M}=\mathrm{Ti}$, $\mathrm{Zr}$, and Hf), [88,89] detailing the impact of the length of the linker and of the metal centers on their band gap structures. Decreasing band gaps are observed with longer linkers, i.e. from UiO-66 to UiO-68, due to additional carbon states appearing in the top valence band. It is shown that for all three UiOs structures, the band gap is larger for the hydroxylated than the dehydroxylated structures, interpretated in terms of less bound oxygen states in the dehydroxylated structure. In UiO-66, the band gap is shown to decrease both computationally and experimentally when one hydrogen of the bdc linker is substituted with $\mathrm{NO}_{2}$ and even further with $\mathrm{NH}_{2}$ substitution. For the latter, the reduced band gap emanates from a decreased binding energy which results from the repulsive interaction between the lone pair associated with nitrogen atom and the delocalized metal centre states. 
Another example of the dominant impact of the linker in the resulting optical band gap is provided in the recent study of the post-synthetically modified Rh@UiO-67 [90]. For the purpose of further performing $\mathrm{CO}_{2}$ photocatalytical reduction, the parent UiO-67 (based on biphenyldicarboxylate, bpdc) is used as the immobilization platform for the Rh-based molecular catalyst, namely $\mathrm{Cp} * \mathrm{Rh}(\mathrm{bpydc}) \mathrm{Cl}_{2}\left(\mathbf{b p y d c}=2,2^{\prime}-\right.$ bipyridine-5,5'-dicarboxylic acid). The bpdc linker is post-synthetically exchanged with bpydc, leading to a Rh-functionalized Cp*Rh@UiO-67 solid (Fig. 11A-B). The optical BG value for $\mathrm{Cp} * \mathrm{Rh} @ \mathrm{UiO}-67$ is of $2.4 \mathrm{eV}$, and represents a decrease of $1.1 \mathrm{eV}$ relative to the parent $\mathrm{UiO}-67$, in agreement with that computed for the $\mathrm{Cp} * \mathrm{Rh} @ \mathrm{UiO}-67$ model structure. The calculations further show that the HOMO-LUMO energy levels in all pristine and post-exchanged UiO-67s (bpdc, bpydc-exchanged, Rh-bpydcfunctionalized) are identical to those obtained for the corresponding single linker molecules (Fig. 11C), confirming the dominant role of the linker in the optical properties in the sub-class of MOFs.

An interesting discovery arised in the photochromism of a framework material built from $\mathrm{TiO}_{2}$ octahedrons, MIL-125 [91], where an explanation for the striking white-to-black color change on UV excitation was provided on the basis of DFT calculations by Walsh and Catlow [92]. By examining the electronic and defect structure of this hybrid titanium system, they propose the origin of its remarkable photochromic properties. Band gap excitations (charge transfer from the organic to inorganic units) were found to have sufficient energy to create lattice vacancies, which results in the formation of gaseous $\mathrm{O}_{2}$ coupled with the reversible reduction of $\mathrm{Ti}(\mathrm{IV})$ to photoactive Ti(III) ions. Importantly, the analysis of the electronic and defect structure of MIL-125 reveals a spatial separation of charges (electrons versus holes) between the 
organic and inorganic subnetworks, as a lower-energy process than in bulk $\mathrm{TiO}_{2}$ and that of the band gap, explaining the facile colour change of MIL-125 under UV light.

The photostimulated chemical reduction of this prototypical MIL-125 material suggests immense potential developments of photochemical applications through the tailoring the MOFs and their band gap, a still emerging area. This is particularly well exemplified in the case of MIL-125. When synthesized with 1,4-benzenedicarboxylate (bdc), MIL-125 exhibits an optical band gap in the UV region (ca $3.6 \mathrm{eV}$ ) [91]. When synthesized with a mono-aminated bdc linker, MIL-125- $\mathrm{NH}_{2}$ exhibits photocatalytical activity for $\mathrm{CO}_{2}$ reduction with an extra absorption band in the visible region associated with a reduced optical band gap (to ca. $2.6 \mathrm{eV}$ ) [93]. Our electronic structure calculations have later confirmed the specific role of the $-\mathrm{NH}_{2}$ group in lowering the optical band gap, bringing also the experimental confirmation that a single $-\mathrm{NH}_{2}$ motif is responsible for the observed shift towards visible [94]. The computational exploration was extended to other potential analogues of MIL-125 containing weaker or stronger electron-donating substituents for the bdc linker $\left(\mathrm{X}=-\mathrm{CH}_{3},-\mathrm{Cl},-\mathrm{OH},-\mathrm{NH}_{2},-\left(\mathrm{NH}_{2}\right)_{2}\right)$ (Fig. 12). Among these variously substituted bdc linkers, the diaminated bdc- $\left(\mathrm{NH}_{2}\right)_{2}$ linker was expected to demonstrate the most significant red shift with a further reduced optical band gap of $1.28 \mathrm{eV}$. This computational prediction was further confirmed by the targeted synthesis of a mixed mono-aminated/diaminated bdc-MIL-25 (i.e.10\%MIL-125-( $\left.\left.\mathrm{NH}_{2}\right)_{2} / 90 \%-\mathrm{MIL}-125-\mathrm{NH}_{2}\right)$ exhibiting the expected shift towards the visible. This particular work illustrates the efficacy of combined computational and experimental strategies.

\section{Concluding remarks}


We have described a few advances towards the prediction of crystal structures of MOFs and the important role that modeling plays in identifying in silico potentially interesting new materials, often prior to any experimental synthetic efforts. We have especially tried to highlight the use of simulation-informed design principles to target and further synthesize targeted new hybrid materials. Overall, the rich and vast landscape of hybrid materials can be navigated with the aid of modelling by screening materials, identifying desirable (and undesirable) structures and properties. The ability to probe large numbers of known or hypothetical structures offers exciting prospects for mining databases and establishing procedures to help the goal of designing a material with tailored properties and functionalities. With no doubt, computational approaches will continue to provide pivotal contributions to the development and direction of the field of hybrid materials, as exemplified with the recent computational exploration of genuine conducting MOFs [95]. Although computational chemistry is now at the forefront of the search of new hybrid materials, one major challenge remains whereby simulations could also predict how such new MOFs might be synthesized. This is a multiscale problem which cannot be addressed by currently available computational approaches, mainly because complex kinetics aspects involved in synthesis or nucleation processes of MOFs remain to be tackled. 


\section{References}

1. Price, S. L. (2008). From crystal structure prediction to polymorph prediction: interpreting the crystal energy landscape, Phys. Chem. Chem. Phys., 10, 19962009.

2. Jones, J. T. A., Hasell, T., Wu, X. F., Bacsa, J., Jelfs, K. E., Schmidtmann, M., Chong, S. Y., Adams, D. J., Trewin, A., Schiffman, F., Cora, F., Slater, B., Steiner, A., Day, G. M., Cooper, A. I. (2011). Modular and predictable assembly of porous organic molecular crystals, Nature, 474, 367-371.

3. Mellot-Draznieks, C. (2007). Role of computer simulations in structure prediction and structure determination: from molecular compounds to hybrid frameworks, $J$. Mater. Chem., 17, 4348-4358.

4. Woodley, S. M., Catlow, R. (2008) Crystal structure prediction from first principles, Nat. Mater., 7, 937-946.

5. Gautier, R., Zhang, X. W., Hu, L. H., Yu, L. P., Lin, Y. Y., Sunde, T. O. L., Chon, D., Poeppelmeier, K. R., Zunger, A. (2015). Prediction and accelerated laboratory discovery of previously unknown 18-electron ABX compounds, Nature Chem. 7 , 308-316.

6. Kirkpatrick, S., Gellat, J. C. D., Vecchi, M. P. (1983). Optimization by simulated annealing, Science, 220, 671-680.

7. Wales, D. J., Scheraga, H. A. (1999). Review: chemistry. Global optimization of clusters, crystals, and biomolecules, Science, 285, 1368-1372.

8. Coley, D. A. An Introduction to Genetic Algorithms for Scientists and Engineers (World Scientific, 1999). 
9. Foster, M. D, Simperler, A. Bell, R. G., Friedichs, O. D., Paz, F. A. A., Klinowski, J. (2004). Chemically feasible hypothetical crystalline networks, Nat. Mater., 3, 234-238.

10. O'Keeffe, M. (2008). Three-periodic nets and tilings: regular and related infinite polyhedral, Acta Crystallogr. A, 64, 425-429.

11. Martoňak, R., Donadio, D., Oganov, A. R., Parrinello, M. (2006). Crystal structure transformations in $\mathrm{SiO}_{2}$ from classical and ab initio metadynamics, Nat. Mater., 5, 623-626.

12. Mellot-Draznieks, C., Newsam, J. M., Gorman, A. M., Freeman, C. M., Férey, G. (2000). De novo prediction of inorganic structures developed through automated assembly of secondary building units (AASBU method), Angew. Chem. Int. Ed., 39, 2270-2275.

13. Mellot-Draznieks, C., Férey, G., Schön, C., Cancarevic, Z., Jansen, M. (2002). Computational design and prediction of interesting not-yet-synthesized structures of inorganics materials using building unit concepts, Chem. Eur. J., 8, 4102-4113.

14. Mellot-Draznieks, C., Girard, S., Férey, G. (2002). Novel inorganic frameworks constructed from double-four-ring (D4R) units: computational design structures and lattice energies of silicate, aluminophosphate and gallophosphate candidates, J. Am. Chem. Soc., 124, 15326-15335.

15. Mellot-Draznieks, C., Dutour, J., Férey, G. (2004). Hybrid organic-inorganic frameworks: routes for computational design and structure prediction, Angew. Chem., Int. Ed., 43, 6290-6296.

16. Mellot-Draznieks, C., Férey, G. (2005). Assembling molecular species into 3D frameworks: computational design and structure solution of hybrid materials, Prog. Solid. State. Chem., 33, 187-197. 
17. Mellot-Draznieks, C. (2007). Role of computer simulations in structure prediction and structure determination: from molecular compounds to hybrid frameworks, $J$. Mater. Chem., 17, 4348-4358.

18. Férey, G., Serre, C., Mellot-Draznieks, C., Millange, F., Surblé, S., Dutour, J., Margiolaki, I. (2004). A hybrid solid with giant pores prepared by a combination of targeted chemistry, simulation and powder diffraction, Angew. Chem., Int. Ed., 43, 6296-6301.

19. Férey, G., Mellot-Draznieks, C., Serre, C., Millange, F., Dutour, J., Surblé, S., Margiolaki, I. (2005). A chromium terephthalate-based solid with unusually large pore volumes and surface area, Science, 309, 2040-2042.

20. Wilmer, C. E., Leaf, M., Lee, C. Y., Farha, O. K., Hauser, B. G., Hupp, J. T., Snurr, R. Q. (2012). Large-scale screening of hypothetical metal-organic frameworks, Nat. Chem. 4, 83-89.

21. Babarao, R., Jiang, J. W. (2008). Molecular screening of metal-organic frameworks for $\mathrm{CO}_{2}$ storage, Langmuir, 12, 6270-6278.

22. Li, J. R., Kuppler, R. J., Zhou, H. C. (2009). Selective gas adsorption and separation in metal-organic frameworks, Chem. Rev. Soc., 38, 1477-1504.

23. Getman, R. B., Bae, Y. S., Wilmer, C. E., Snurr, R. Q. (2012). Review and analysis of molecular simulations of methane, hydrogen, and acetylene storage in metal-organic-framworks, Chem. Rev., 112, 703-723.

24. Sikora, B. Wilmer, C. E, Greenfield M. L., Snurr R. Q. (2012). Thermodynamic analysis of $\mathrm{Xe} / \mathrm{Kr}$ selectivity in over 137,000 hypothetical metal-organic frameworks, Chem. Sci., 7, 2217-2223. 
25. Wilmer, C E., Farha, O. K., Bae, Y.-S., Hupp, J. T., Snurr, R. Q. (2012). Structure-property relationships of porous materials for carbons dioxide separation and capture, Energy Environ. Sci., 12, 9849-9856.

26. Amrouche, H., Aguado, S., Perez-Pellitero, J., Chizallet, C., Siperstein, F., Farrusseng, D., Bats, N., Nieto-Draghi, C. (2011). Experimental and computational study of functionality impact on sodalite-zeolitic imidazolate frameworks for $\mathrm{CO}_{2}$ separation, J. Phys. Chem. C, 115, 16425-16432.

27. Amrouche, H., Creton, B., Siperstein, F., Nieto-Draghi, C. (2012). Prediction of thermodynamic properties of adsorbed gases in zeolitic imidazolate frameworks, RSC Adv., 2, 6028-6035.

28. Gaudin, C., Cunha, D., Ivanoff, E., Horcajada, P., Cheve, G., Yasri, A., Loget, O., Serre, C. (2012). A quantitative structure activity relationship approach to probe the influence of the functionalization on the drug encapsulation of porous metalorganic frameworks, Microporous Mesoporous Mater., 157, 124-130.

29. Special issue on polyoxometalates (2007). J. Mol. Catal. A, 1-2, 1-242.

30. Mitchell, S. G., Streb, C., Miras, H. N., Boyd, T., Long, D. L., Cronin, L. (2010). Face-directed self-assembly of an electronically active Archimedean polyoxometalate architecture, Nat. Chem., 2, 308-312.

31. Zheng, S. T., Zhang, J., Yang, G. Y. (2009). Designed synthesis of POM-organic frameworks from $\{\mathrm{Ni}(6) \mathrm{PW}(9)\}$ building blocks under hydrothermal conditions, Angew. Chem., Int. Ed., 47, 3909-3913.

32. Dolbecq, A., Mialane, P., Sécheresse, F., Keita, B., Nadjo, L. (2012). Functionalized polyoxometalates with covalently linked bisphosphonates, Ndonor or carboxylate ligands: from electrocatalytic to optical properties, Chem. Commun., 48, 8299-8316. 
33. Dolbecq, A., Dumas, E., Mayer, C. R., Mialane, P. (2010). Hybrid organicinorganic polyoxometalate compounds: from structural diversity to applications, Chem. Rev., 110, 6009-6048.

34. Du, D.Y., Qin, J.S., Li, S.L., Su, Z.M., Lan Y.Q. (2014). Recent advances in porous polyoxometalate-based metal-organic framework materials, Chem. Soc. Rev. 43, 4615-4632.

35. Ockwig, N. W., Delgado-Friedrichs, O., O’Keeffe, M., Yaghi, O. M. (2005). Reticular chemistry: occurrence and taxonomy of nets and grammar for the design of frameworks, Chem. Res., 38, 176-182.

36. Dolbecq, A., Mellot-Draznieks, C., Mialane, P., Marrot, J., Férey, G., Sécheresse, F. (2005). Hybrid 2D and 3D frameworks based on epsilon-Keggin polyoxometallates: experiment and simulation, Eur. J. Inorg. Chem., 15, 30093018.

37. International Zeolite Association, http://www.iza-structure.org/databases.

38. Park, K. S., Ni, Z., Cote, A. P., Choi, J. Y., Huang, R. D., Uribe-Romo, F. J., Chae, H. K., O’Keeffe, M., Yaghi, O. M. (2006). Exceptional chemical and thermal stability of zeolitic imidazolate frameworks, Proc. Natl. Acad. Sci. U S A, 103, 10186-10191.

39. Mialane, P., Dolbecq, A., Lisnard, L., Mallard, A., Marrot, J., Scheresse, F. (2002). [Epsilon- $\left.\mathrm{PMo}_{12} \mathrm{O}_{36}(\mathrm{OH})_{4}\left\{\mathrm{La}\left(\mathrm{H}_{2} \mathrm{O}\right)_{4}\right\}_{4}\right](5)$ : the first epsilon- $\mathrm{PMo}_{12} \mathrm{O}_{40}$ Keggin ion and its association with the two-electron-reduced alpha- $\mathrm{PMo}_{12} \mathrm{O}_{40}$ isomer, Angew. Chem., Int. Ed., 41, 2398-2401.

40. Rodriguez-Albelo, L. M., Ruiz-Salvador, A. R., Sampieri, A., Lewis, D. W., Gomez, A., Nohra, B., Mialane, P., Marrot, J., Sécheresse, F., Mellot-Draznieks, C., Biboum, R. N., Keita, B., Nadjo, L., Dolbecq, A. (2009). Zeolitic 
polyoxometalate-based metal-organic frameworks (Z-POMOFs): computational evaluation of hypothetical polymorphs and the successful targeted synthesis of the redox-active Z-POMOF1, J. Am. Chem. Soc., 131, 16078-16087.

41. Ruiz-Salvador, A. R., Gomez, A., TOBUNPOROUS code. Code available from authors.

42. Rodriguez-Albelo, L. M., Ruiz-Salvador, A. R., Lewis, D. W., Gomez, A., Mialane, P., Marrot, J., Dolbecq, A., Sampieri, A., Mellot-Draznieks, C. (2010). Zeolitic polyoxometalate-based metal-organic frameworks (Z-POMOFs) with imidazole ligands and e-Keggin ions as building blocks, computational evaluation of hypothetical polymorphs and a synthesis approach, Phys. Chem. Chem. Phys., 12, 8632-8640.

43. Rodriguez-Albelo, L. M., Rousseau, G., Mialane, P., Marrot, J., MellotDraznieks, C., Ruiz-Salvador, A. R., Li, S., Lui, R., Zhang, G., Keita, B., Dolbecq, A. (2012). $\varepsilon$-Keggin-based coordination networks: synthesis, structure and application toward green synthesis of polyoxometalate@ graphene hybrids, Dalton Trans., 41, 9989-9999.

44. Nohra, B., Moll, H. E., Albelo, M. R., Mialane, P., Marrot, J., Mellot-Draznieks, C., O’Keeffe, M., Biboum, R. N., lemaire, J., Keita, B., Nadjo, L., Dolbecq, A. (2011). Polyoxometalate-based metal organic framework (POMOFs): structural trends, energetics and high electrocatalytical efficiency for hydrogen evolution reaction, J. Am. Chem. Soc., 133, 13363-13374.

45. We refer here to the RCSR database (hhtp://rcsr.anu.edu.au) developed by M. O'Keeffe designed for easily classifying nets, giving each net its own three-letter designation. The new "ofp" net refers to open-framework polyoxometalate. See also O’Keeffe, M., Peskov, M. A., Ramsden, S. J., Yaghi, O. M. (2008). The 
reticular chemistry structure resource (RCSR) database of, and symbols for, crystal nets, Acc. Chem. Res., 41, 1782-1789.

46. El-Kaderi, H. M., Hunt, J. R., Mendoza-Cortes, J. L., Cote, A. P., Taylor, R. E., O'Keeffe, M., Yaghi, O. M. (2007). Designed synthesis of 3D covalent organic frameworks, Science, 316, 268-272.

47. Banerjee, R., Phan, A., Wang, B., Knobler, C., Furukawa, H., O’Keeffe, M., Yaghi, O.M. (2008). High-throughput synthesis of zeolitic imidazolate frameworks and application to $\mathrm{CO}_{2}$ capture, Science, 319, 939.

48. Huang, X.-C., Lin, Y.-Y., Zhang, J.-P., Chen X.-M. (2006). Ligand-directed strategy for zeolite-type metal-organic frameworks: Zinc(II) imidazolates with unusual zeolitic topologies, Angew. Chem. Int. Ed, 45, 1557.

49. Amrouche, H., Aguado, S., Pérez-Pellitero, J., Chizallet, C., Siperstein, F., Farrusseng, D., Bats, N., Nieto-Draghi, C. (2011). Experimental and Computational Study of Functionality Impact on Sodalite-Zeolitic Imidazolate Frameworks for $\mathrm{CO}_{2}$ Separation, J. Phys. Chem. C, 115, 16425.

50. Hayashi, H., Côté, A. P., Furukawa, H., O’Keeffe, M., Yaghi, O. M. (2007). Zeolite A imidazolate frameworks, Nat. Mater., 6, 501.

51. Zhang, J.-P., Zhang, Y.-B., Lin, J.-B., Chen, X.-M. (2012). Metal Azolate Frameworks: From Crystal Engineering to Functional Materials, Chem. Rev, 112, 1001

52. Baburin, I. A., Leoni, S., Seifert, G. (2008). Enumeration of not-yet-synthesized zeolitic zinc imidazolate MOF networks: a topological and DFT approach, $J$. Phys. Chem. B, 112, 9437-9443.

53. Lewis, D. L., Ruiz-Salvador, R. A., Gomez, A., Rodriguez-Albelo, Coudert, F. X., Slater, B., Cheetham, A. K., Mellot-Draznieks, C. M. (2009). Zeolitic imidazole 
frameworks: structural and energetics trends compared with their zeolitic analogues, Cryst. Eng. Commun., 11, 2272-2276.

54. Galvelis, R., Slater, B., Cheetham, A. K., Mellot-Draznieks, C. M. (2011). Comparison of the stability of zinc and lithium-boron zeolitic imidazole frameworks, Cryst. Eng. Commun., 14, 374-378.

55. Hugues, J. T., Bennett, T. D., Cheetham, A. K., Navrotsky, A. (2013). Thermochemistry of zeolitic imidazolate frameworks of varying porosity, J. Am. Chem. Soc., 135, 598-601.

56. Walker, A. M., Civalleri, B., Slater, B., Mellot-Draznieks, C., Cora, F., ZicovichWilson, C. M., Roman-Perez, G., Soler, J. M., Gale, J. D. (2010). Flexibility in a Metal-Organic Framework Material Controlled by Weak Dispersion Forces: The Bistability of MIL-53(Al), Angew. Chem. Int. Ed., 49, 7501.

57. Galvelis, R; Slater, B.; Chaudret, R.; Creton, B.; Nieto-Draghi, C.; MellotDraznieks, C. (2013). Impact of functionalized linkers on the energy landscape of ZIFs. CrystEngComm. 15, 9603-9613.

58. Ma, L. Q., Abney, C., Lin, W. B. (2009). Enantioselective catalysis with homochiral metal-organic frameworks, Chem. Soc. Rev., 38, 1248-1256.

59. Lee, C., Mellot-Draznieks, C., Slater, B., Wu, G., Harrison, W. T. A., Rao, C. N. R., Cheetham, A. K. (2006). Thermodynamic and kinetic factors in the hydrothermal synthesis of hybrid frameworks: zinc 4-cyclohexene-1,2dicarboxylates, Chem. Commun., 2687-2689.

60. Harvey, H. G., Slater, B., Attfield, M. P. (2004). Rational design of the pore system within the framework aluminum alkylenediphosphonate series, Chem.Eur. J., 10, 3270-3278. 
61. Bailey, A. J., Lee, C., Feller, R. K., Orton, J. B., Mellot-Draznieks, C., Slater, B., Harrison, W. T. A., Simoncic, P., Navrotsky, A., Grossel, M. C., Cheetham, A. K. (2008). Comparison of chiral and racemic forms of zinc cyclohexane trans-1,2dicarboxylate frameworks: a structural, computational, and calorimetric study, Angew. Chem., Int. Ed., 47, 8634-8637.

62. Greathouse, J. A., Allendorf, M. D. (2006). Interaction of water with MOF-5 simulated by molecular dynamics, J. Am. Chem. Soc., 128, 10678-10679.

63. Appelhans, L. N., Kosa, M., Radha, A. V., Simoncic, P., Navrotsky, A., Parrinello, M., Cheetham, A. K. (2009). Phase selection and energetics in chiral alkaline earth tartrates and their racemic and meso analogues: synthetic, structural, computational and calorimetric studies, J. Am. Chem. Soc., 131, 15375-15386.

64. Yeung, H. H.-M., Kosa, M., Parrinello, M., Forster, P. M., Cheetham, A. K. (2011). Structural diversity and energetics in anhydrous lithium tartrates: experimental and computational studies of novel chiral polymorphs and their racemic and meso analogues, Cryst. Growth Design, 11, 221-230.

65. Allendorf, M. D., Schwartzberg, A., Stavila, V., Talin A. A. (2011), A roadmap to implementing metal-organic frameworks in electronic devices: challenges and critical directions, Chem. Eur. J., 17, 11372-11388.

66. Cheetham, A. K., Rao, C. N. R. (2007). There is room in the middle, Science, 318, 58-59; Rao, C. N. R., Cheetham, A. K., Thirumurugan, A. (2008). Hybrid inorganic-organic materials: a new family in condensed matter physics, J. Phys.: Condens. Matter, 20, 083202.

67. Silva, C. Gomes, Corma, A., Garcia, H. (2010), Metal-organic frameworks as semiconductors, J. Mater. Chem., 20, 3141-3156. 
68. Wang, C., Xie, Z. G., de Krafft, K. E., Lin, W. L. (2011). Doping metal organic frameworks for water oxidation, carbon dioxide reduction and organic photocatalysis, J. Am. Chem. Soc., 133, 13445-13454.

69. Stavila, V., Talin, A. A., Allendorf, M. D. (2014). MOF-based electronic and opto-electronic devices, Chem. Soc. Rev., 43, 5994-6010.

70. Foster, M. E., Azoulay, J. D., Wrong, B. M., Allendorf, M. D. (2014). Novel metal-organic framework linkers for light harvesting applications, Chem. Sci., 5, 2081-2090.

71. Horiuchi, Y., Toyao, T., Takeuchi, M., Matsuoka, M., Masakazu, A. (2013). Recent advances in visible-light-responsive photocatalyst for hydrogen production and solar energy conversion - from semiconducting $\mathrm{TiO}_{2}$ to $\mathrm{MOF} / \mathrm{PCP}$ photocatalysts, Phys. Chem. Phys. Chem., 15, 13243-13253.

72. Zhang, T., Lin, W. (2014). Metal-organic frameworks for artificial photosynthesis and photocatalysis. Chem. Soc. Rev., 43, 5982-5993.

73. Civalleri, B., Napoli, F., Noël, Y., Roetti, C., Dovesi, R. (2006). Ab initio prediction of materials properties with CRYSTAL: MOF-5 as a case study, Cryst. Eng. Commun., 8, 364-371.

74. Kuc, A., Enyashin, A., Seifert, G. (2007). Metal-organic frameworks: structural, energetic, electronic, and mechanical properties, J. Phys. Chem. B, 111, 81798186.

75. Gascon, J., Hernandez-Alonso, M. D., Almeida, A. R., van Klink, G. P. M., Kapteijn, F., Mul, G. (2008). Isoreticular MOFs as efficient photocatalysts with tunable band gap: an operando FTIR study of the photoinduced oxidation of propylene, ChemSusChem, 1, 981-983. 
76. Yang, LM, Vajeeston P, Ravindran P., Fjellvag, H.; Tilset, M. (2010). Theoretical Investigations on the Chemical Bonding, Electronic Structure, and Optical Properties of the Metal-Organic Framework MOF-5. Inorg. Chem., 49, 1028310290.

77. Pham, H. Q., Mai, T., Pham-Tran, N.-N., Kawazoe, Y., Mizuseki, H. (2014). Engineering of Band Gap in Metal-Organic Frameworks by Functionalizing organic linker: a systematic density Functional Theory Investigation, J. Phys. Chem. C, 118, 4567-4577)

78. Fuentes-Cabrera, M., Nicholson, D. M., Sumpter, B. G., Widom, M. (2005). Electronic structure and properties of isoreticular metal-organic-frameworks: the case of M-IRMOF1 (M= Zn, Cd, Be, Mg and Ca), J. Chem. Phys., 123, 124713.

79. Choi, J. H., Choi, Y. J., Lee, J. W., Shin, W. H., Kang, J. K. (2009). Tunability of electronic band gaps from semiconducting to metallic states via tailoring $\mathrm{Zn}$ ions in MOFs with Co ions, Phys. Chem. Chem. Phys., 11, 628-631.

80. Lin, C.-K., Zhao, D., Gao, W.-Y., Yang, Z., Ye, J., Xu, T., Ge, Q., Ma, S., Liu, D.-J. (2012), Tunability of band gaps in metal-organic frameworks, Inorg. Chem., 51, 9039-9044.

81. Choi, J. H., Jeon, H. J., Choi, K. M., Kang, J. K. (2012). Metal-organic frameworks for visible light absorption via anion substitution, J. Mater. Chem., 22, 10144-10147.

82. Yang, L.M., Fang, G.Y., Ma, J., Ganz, E., Han, S.S. (2014), Band Gap Engineering of paradigm MOF-5, Cryst. Growth Des. 14, 25322-2541.

83. Hendon, C. H., Tiana, D., Walsh, A. (2012). Conductive Metal-Organic Frameworks and networks: fact or fantasy? Phys. Chem. Chem. Phys. 14, 1312013132. 
84. Butler, K.T., Hendon, C. H., Walsh, A. (2014). Electronic Chemical Potentials of Porous Metal-Organic Frameworks, J. Amer. Chem. Soc. 136, 2703-2706.

85. Cavka, J. H., Jakobsen, S., Olsbye, U., Guillou, N., Lamberti, C., Bordiga, S. , P. Lillerud, K. (2008). A new zirconium inorganic building brick forming metal organic frameworks with exceptional stability, J. Am. Chem. Soc. 130, 13850.

86. Silva, G., Luz, I. , Xamena, F.X.L.I., Corma, A., Garcia, H. (2010). Water Stable Zr-Benzenedicarboxylate Metal-Organic Frameworks as Photocatalysts for Hydrogen Generation, Chem., Eur. J. 36, 11133-11138).

87. Valenzano, L., Civalleri, B., Chavan, S., Bordiga, S., Nilsen, M. H., Jakobsen, S., Lillerud, K. P., Lamberti, C. (2011). Disclosing the complex structure of UiO-66 metal organic framework: a synergic combination of experiment and theory, Chem. Mater., 23, 1700-1718.

88. Flage-Larsen, E., Royset, A., Cavka, J. H., Thorshaug, K. (2013). Band gap modulation in UiO Metal Organic Frameworks. J. Phys. Chem. C, 117, 2061020616.).

89. Yang, L.M., Ganz, E., Svelle, S., Tilset, M. (2014). Computational exploration of newly synthesized zirconium metal-organic frameworks UiO-66, -67, -68 and analogues, J. Mater. Chem., 2, 7111-7125

90. Chambers, M.B., Wang, X., Elgrishi, N., Hendon, C. H., Walsh, A., Bonnefoy, J., Canivet, J., Quadrelli, E. A., Farrusseng, D., Mellot-Draznieks, C., Fontecave, M. (2015). Photocatalytic Carbon Dioxide Reduction with Rhodium-based Catalysts in Solution and Heterogenized within Metal-Organic Frameworks, ChemSusChem, 8, 603-608. 
91. Dan-Hardi, M., Serre, C., Frot, T., Rozes, L., Maurin, G., Sanchez, C. and Férey, G. (2009). A new photoactive crystalline highly porous titatium(IV) dicarboxylate, J. Am. Chem. Soc., 131, 10857.

92. Walsh, A. and Catlow, C. R. A. (2010). Photostimulated reduction processes in a titania hybrid metal-organic framework, ChemPhysChem, 11, 2341-2344.

93. Fu, Y., Sun, D., Chen, Y., Huang, R., Ding, Z., Fu, X., Li, Z. (2012). An AmineFunctionalized Titanium Metal-Organic Framework Photocatalyst with VisibleLight-Induced Activity for $\mathrm{CO}_{2}$ Reduction, Ang. Chem. Int. Ed., 51, 3364-3367.

94. Hendon, C. H., Tiana, D., Fontecave, M., Sanchez, C., d'Arras, L., Sassoye, C., Rozes, L., Mellot-Draznieks, C., Walsh, A. (2013). Engineering the Optical response of the titanium-MIL-125 metal-organic framework through ligand functionalization. J. Am. Chem. Soc. 135, 10942-10945.

95. Walsh, A. (2011). Effects of reduced dimensionality on the electronic structure and defect chemistry of semiconducting hybrid organic-inorganic $\mathrm{PbS}$ solids, Proc. R. Soc. A: Math., Phys. Eng. Sci., 467, 1970-1985; Walsh, A. (2010). Defect processes in a $\mathrm{PbS}$ metal organic framework: a quantum-confined hybrid semiconductor, J. Phys. Chem. Lett., 1, 1284-1287. 
Figure 1. A): Examples of prototypical MOFs predicted with the AASBU method using metal clusters and organic carboxylate linkers commonly found in existing MOFs. Predicted and experimental structural parameters are compared. B): AASBU-based prediction of HKUST-1 using a large hybrid building-block made of pre-assembled $\{\mathrm{Cu} 2\}$ dimers and linkers. C): Examples of not-yet-synthesized MOF predicted in silico.

Figure 2. Analogy between a six-ring in a zeolitic silicate and a six-ring in a ZPOMOF. Reproduced with permission from Ref. [40], Copyright 2009, American Chemical Society.

Figure 3. Hypothetical crystal structures of Z-POMOFs made of $\varepsilon$-Keggin ions and BDC linkers and possessing zeotype topologies. A subselection of uninodal together with multimodal nets is shown. Adapted from Ref. [40], Copyright 2009, American Chemical Society.

Figure 4. Relative lattice energies of hypothetical Z-POMOFs with density. The cristobalite-like Z-POMOF is predicted as the most stable structure among those studied. For comparison the lattice energy of the single net and triply interpenetrated nets of the experimental cristobalite-like Z-POMOF1 is shown for comparison, quantifying the further stabilization emanating from the interpenetration of nets. Reproduced with permission from Ref. [40], Copyright 2009, American Chemical Society. 
Figure 5. (Left) Analogy between ZIFs and the construction of Z-POMOFs from imidazolate and $\varepsilon$-Keggin ions. (Right) Selection of hypothetical Z-POMOFs constructed from dense silicates and zeotypes. Reproduced with permission from [42] from the PCCP Owner Societies.

Figure 6. (Left) View of a four-membered ring in the experimental $\varepsilon(\text { trim })_{4 / 3}$ with a docked and energy-minimized TBA molecule. (Right) Variation of lattice energies with density for the three template-free $\varepsilon(\text { trim })_{4 / 3}$ polymorphs, showing the experimentally observed ofp net as more stable than the two hypothetical bor- and ctn-like polymorphs. Adapted from [44].

Figure 7. NCI analysis of two SOD-type (Li,B)ZIFs, with unsubstituted imidazolate (left) and with 2-methyl-imidazolate (right). The frameworks atoms are represented as coloured spheres, boron (clear blue), lithium (clear pink), carbon (black), hydrogen (grey) and nitrogen (blue). The colour code for NCI surfaces represents strongly attractive interactions (i.e. hydrogen bonds) in clear blue surfaces, very weak interactions (i.e. van der Waals) in green, and repulsive ones (steric clashes) in red. (left): NCI analysis of SOD-Im topology centered on a 6-ring (6R) window; the latter is delineated by a red dashed line (right): NCI analysis of SOD-4-MeIm topology centered on a 6R window; attractive interactions between neighboring $\mathrm{CH}_{3}$ - groups in the 6-ring are visible (green and blue surfaces). Adapted from [57].

Figure 8. Scheme illustrating thermodynamic control during the hydrothermal synthesis of zinc cyclohexene-1,4-dicarboxylates according to Ref. [59]. By courtesy of A. K. Cheetham. 
Figure 9. (Top) The trans-R,R-cyclohexane and trans-S,S-cyclohexane dicarboxylic acids. (Bottom) The dense chiral (left) and less dense racemic (right) structures. Illustration adapted from Ref. [61].

Figure 10: A: Scheme illustrating the approach for calculating the electrostatic potential for MOFs, exemplified here in the case of the MIL-125 titanium-based MOF. a) and b) the crystal structure of MIL-125 where the red spherical electrostatic probe is shown at the centre of the pore. c) valence electron density in $\mathrm{e} / \AA^{3}$ shown in the (001) slice (yellow $=0 \mathrm{e} / \AA^{3}$ to blue=0.5 e/ $\AA^{3}$ ). B: Comparison of ionization energies of the 6 protypic MOFs with respect to the commun vacuum level (ie determined at the center of pores), using DFT calculations with periodic conditions and HSE06 hybrid exchangecorrelation functional. In the case of H-KUST, the various ground state (black), triple (dashed black) and closed-shell singlet (pink) are represented. The redox potential levels for water are indicated. Adapted from ref. [84].

Figure 11. (A): UiO-67 crystal structure; (B): Schematic representation of Cp*Rh@UiO-67; (C): Comparison of the molecular ionisation potentials (left) and solid-state work functions (right). bpdc = biphenyldicarboxyl(ate/ilic acid), 2,2'-bpydc = 2,2' bipyridinedicarboxyl(ate/ilic acid). $\mathrm{Cp}=$ cyclopentadiene, which for simulations is isoelectronic to Cl-. The reference redox potentials shown are in $\mathrm{H}_{2} \mathrm{O}$. Reproduced with permission from Ref. [90], Copyright 2009, American Chemical Society. 
Figure 12. (A): neutral linker molecules explored computationally for the estimation of the optical band gap of MIL-125, including monosubstituted linkers bdc-R (left) and diaminated linker bdc-( $\left.\mathrm{NH}_{2}\right)_{2}$ (right); (B): HSE06-predicted band gaps in the parent MIL-125 (black) and in its analogues containing functionalized bdc linkers. Adapted from ref [94]. 
Figure 1

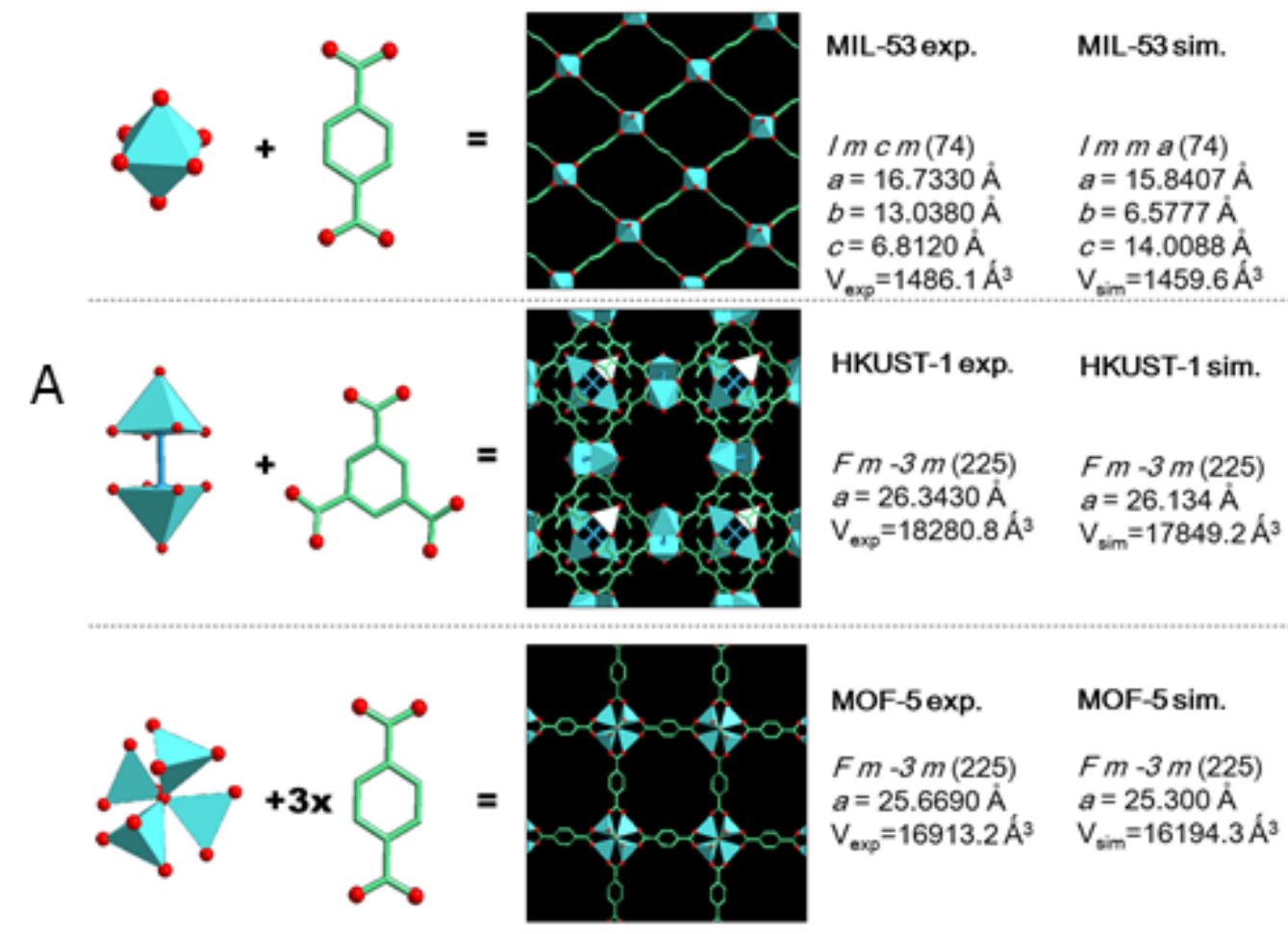

B
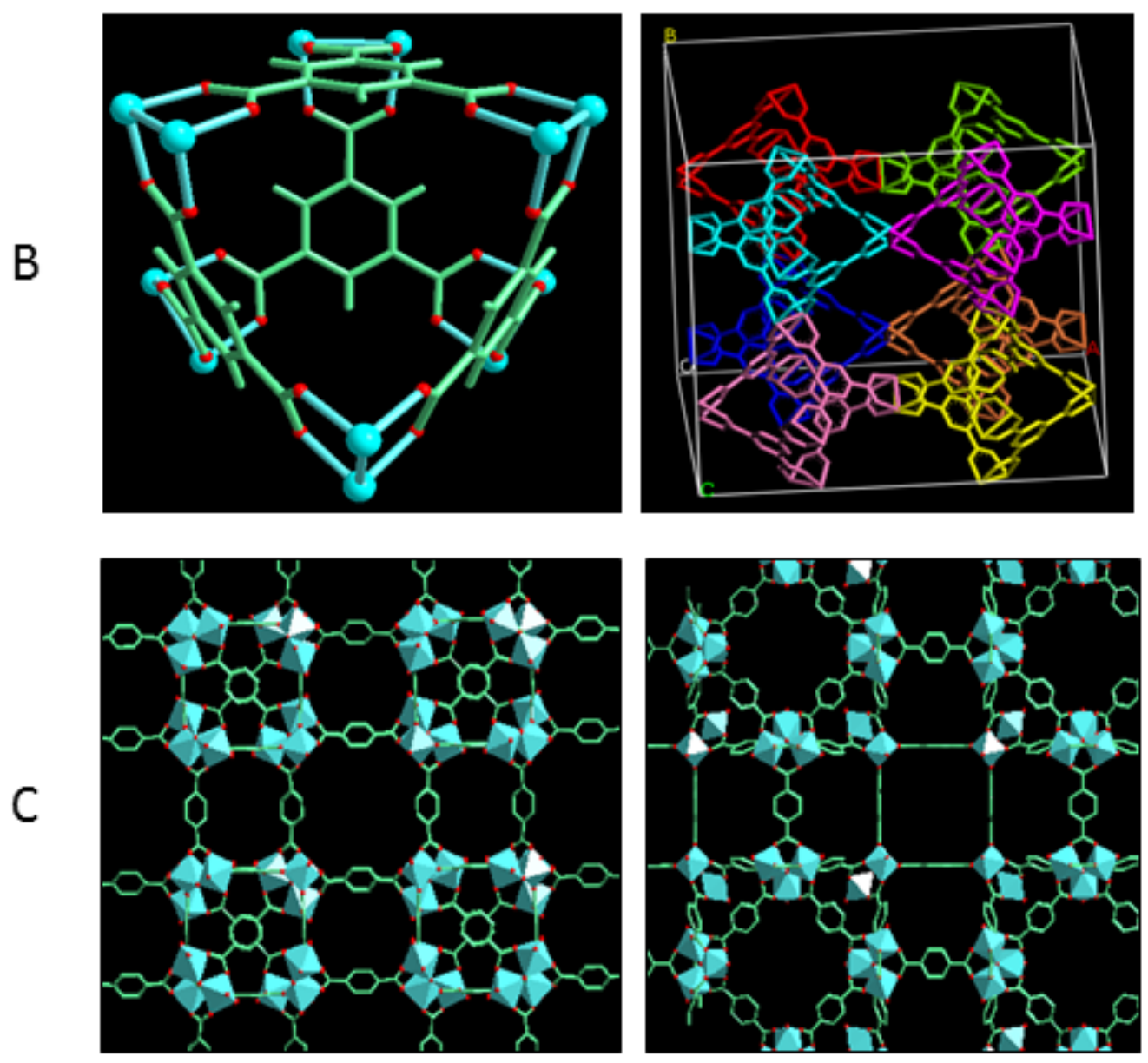
Figure 2

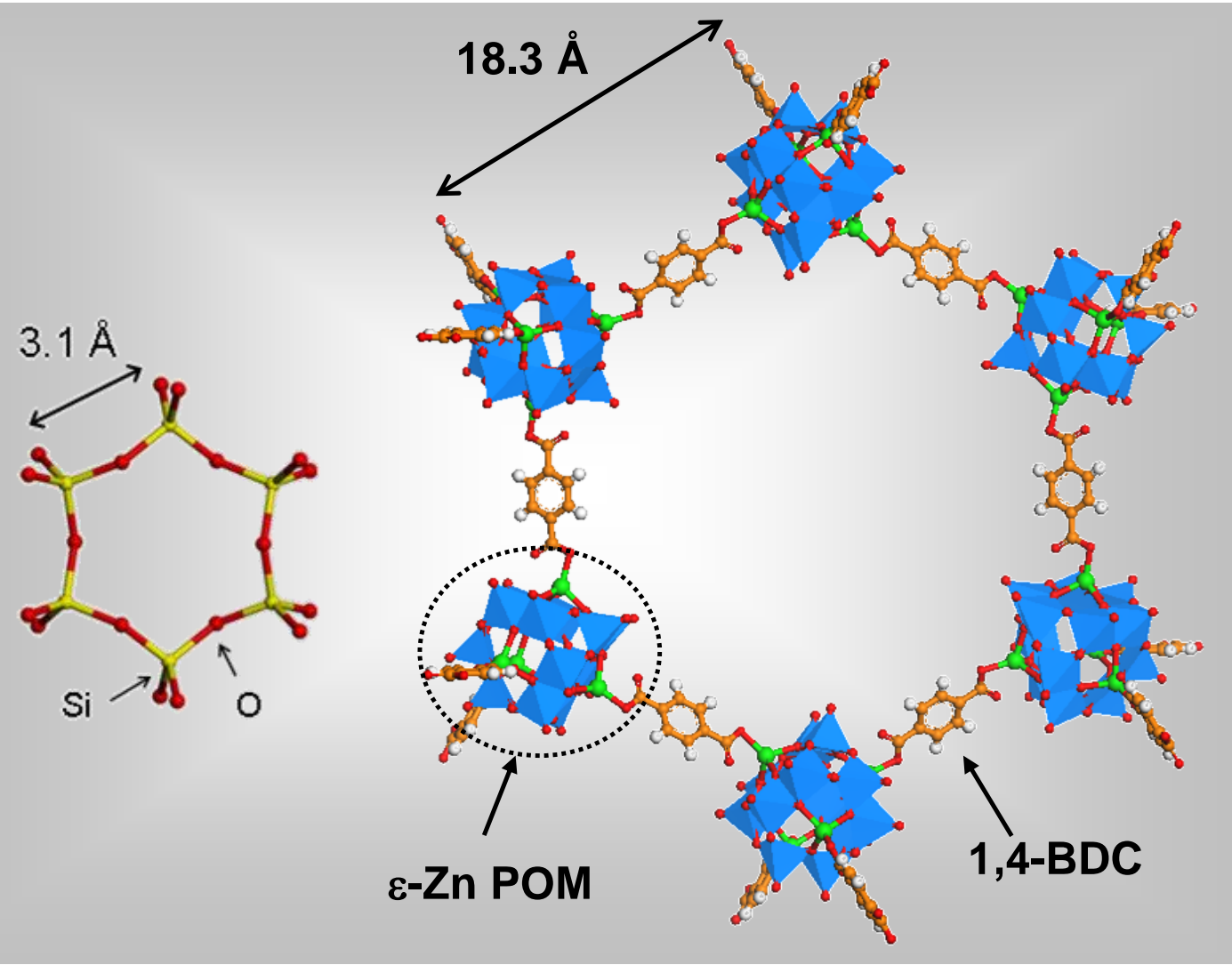


Figure 3
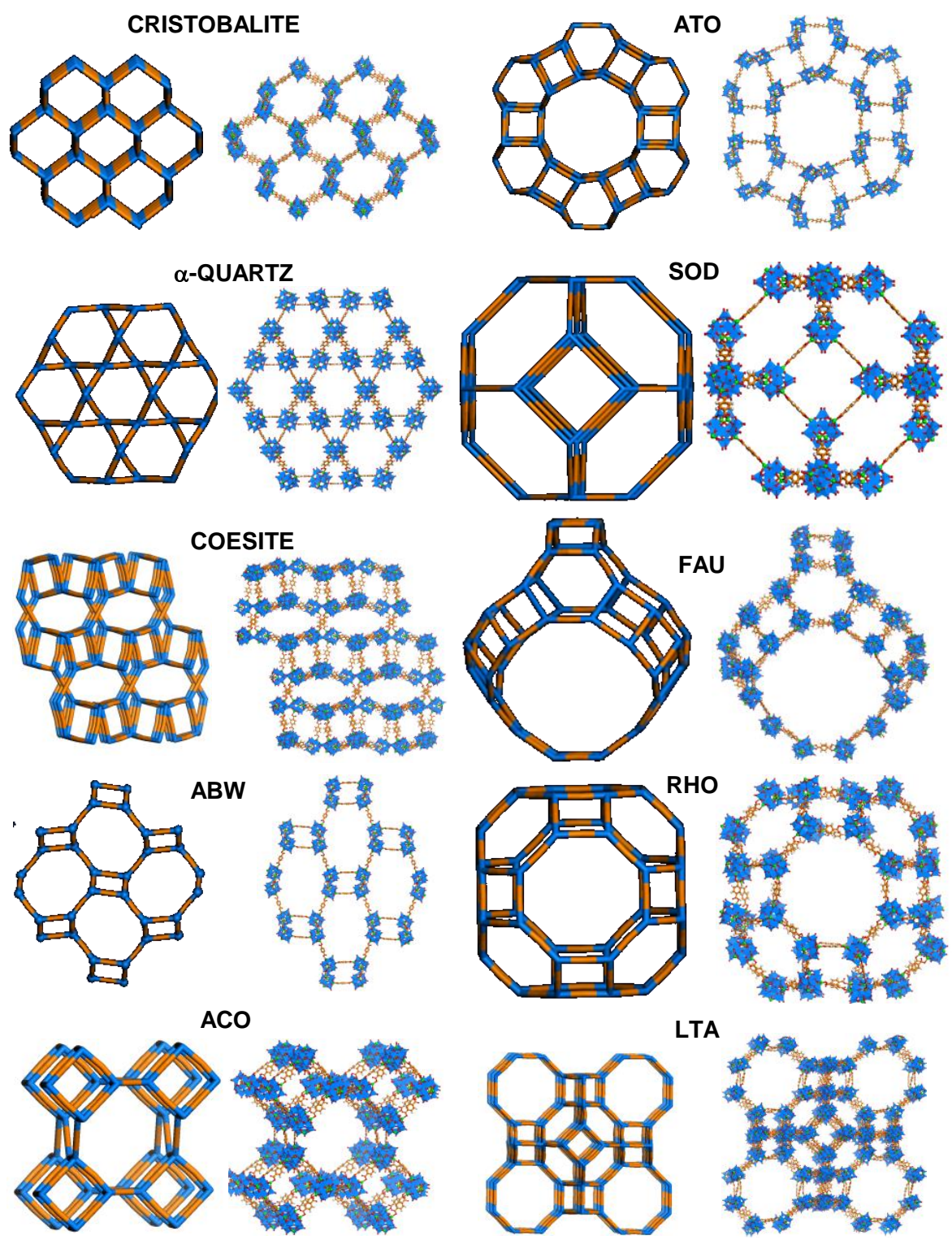

LTA

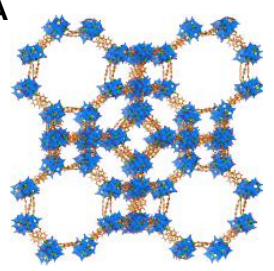


Figure 4

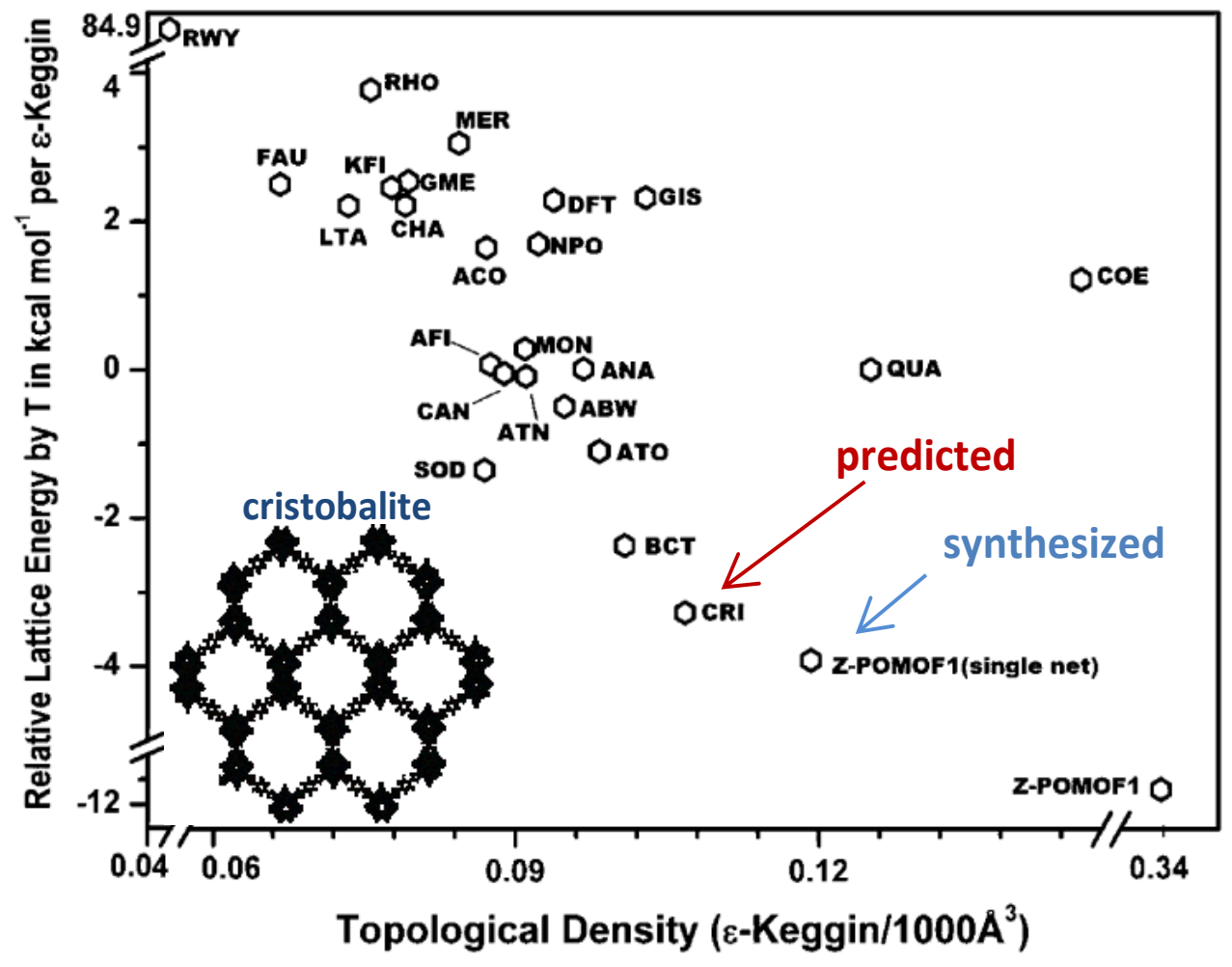




\section{Figure 5}

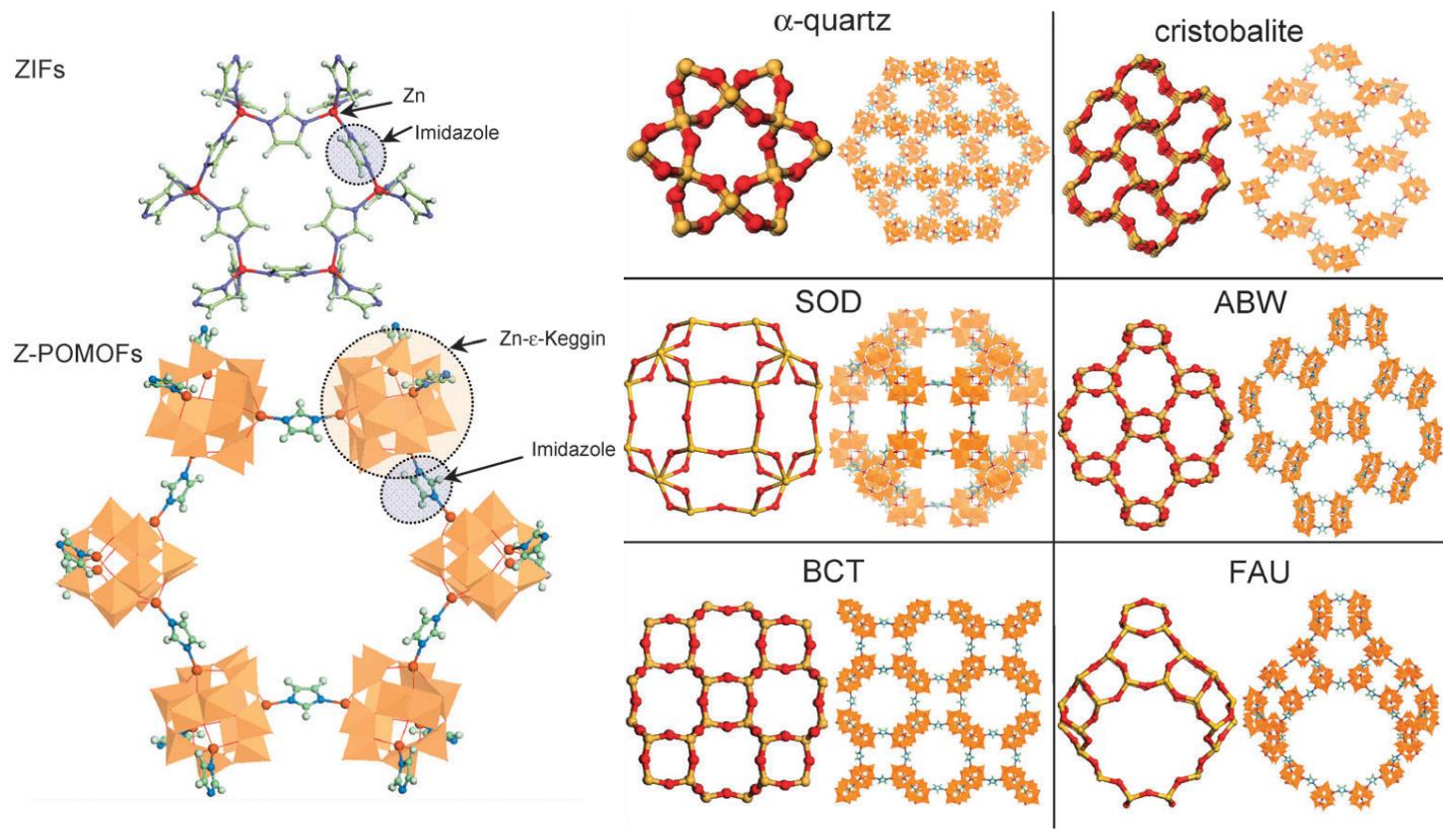


Figure 6
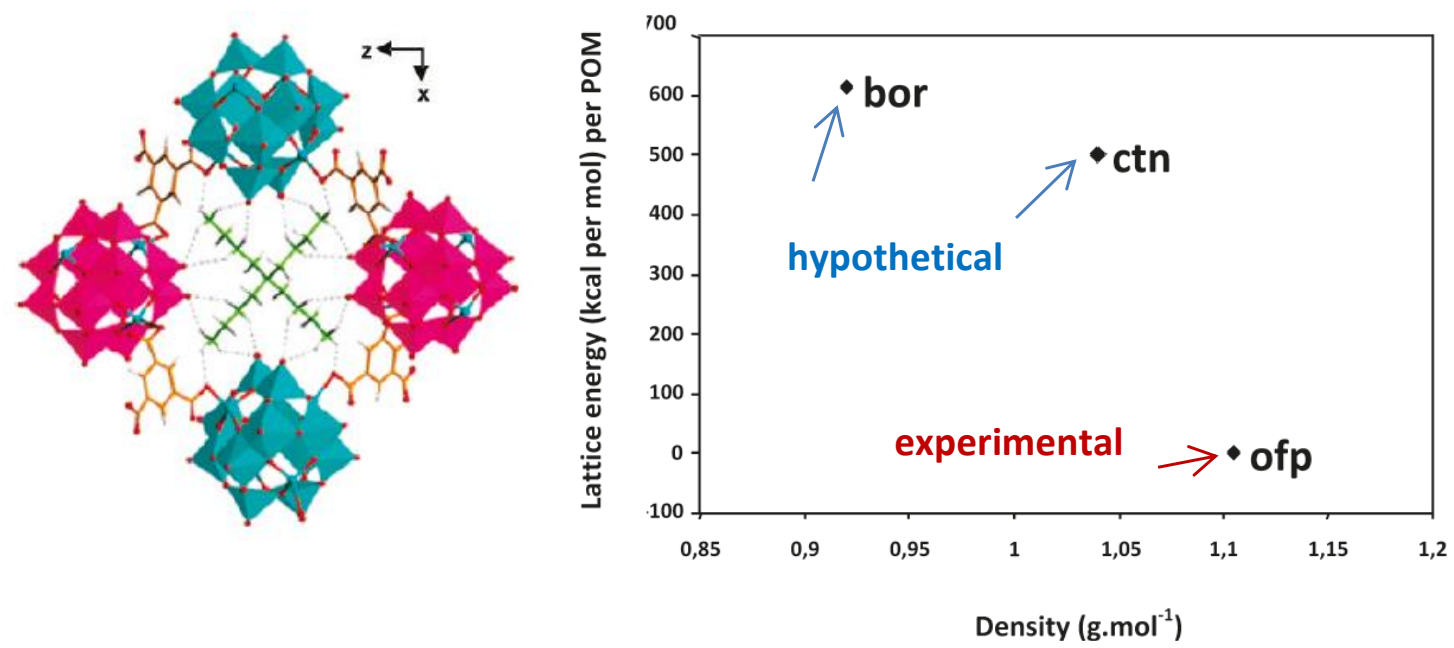
Figure 7
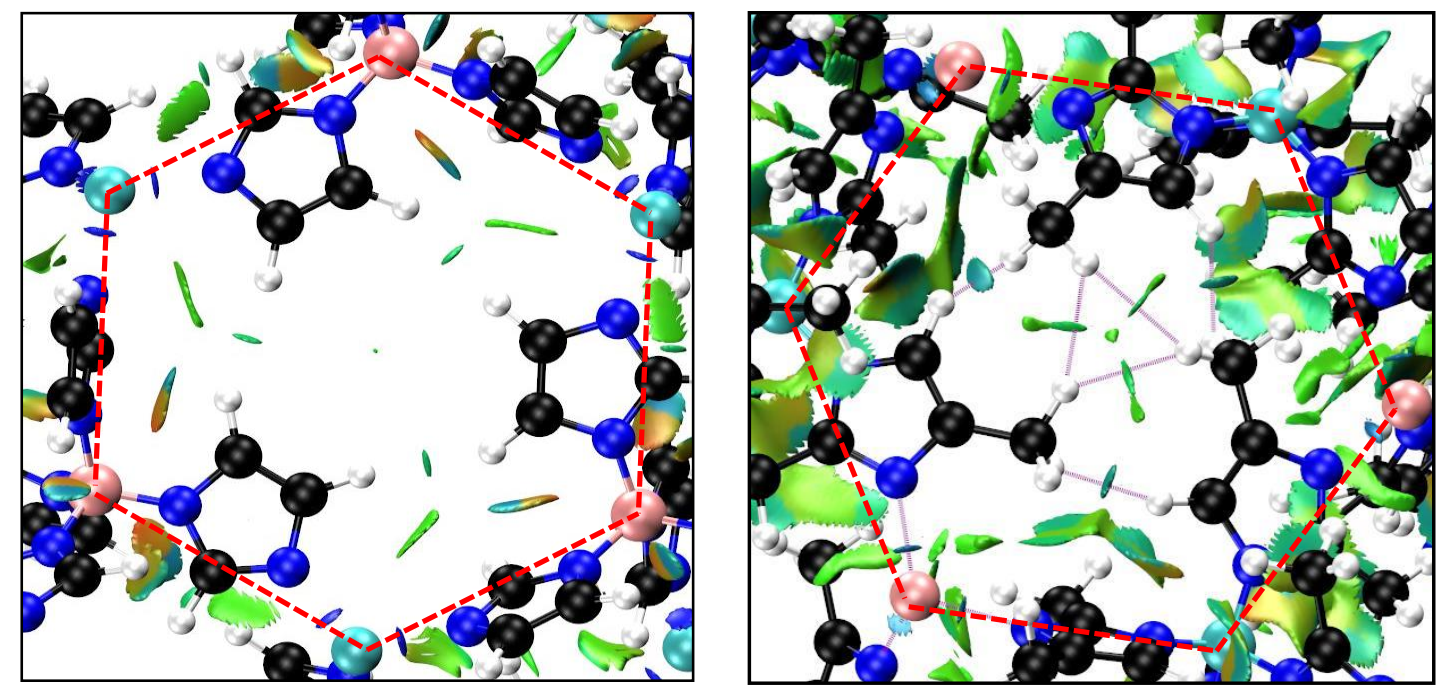


\section{Figure 8}

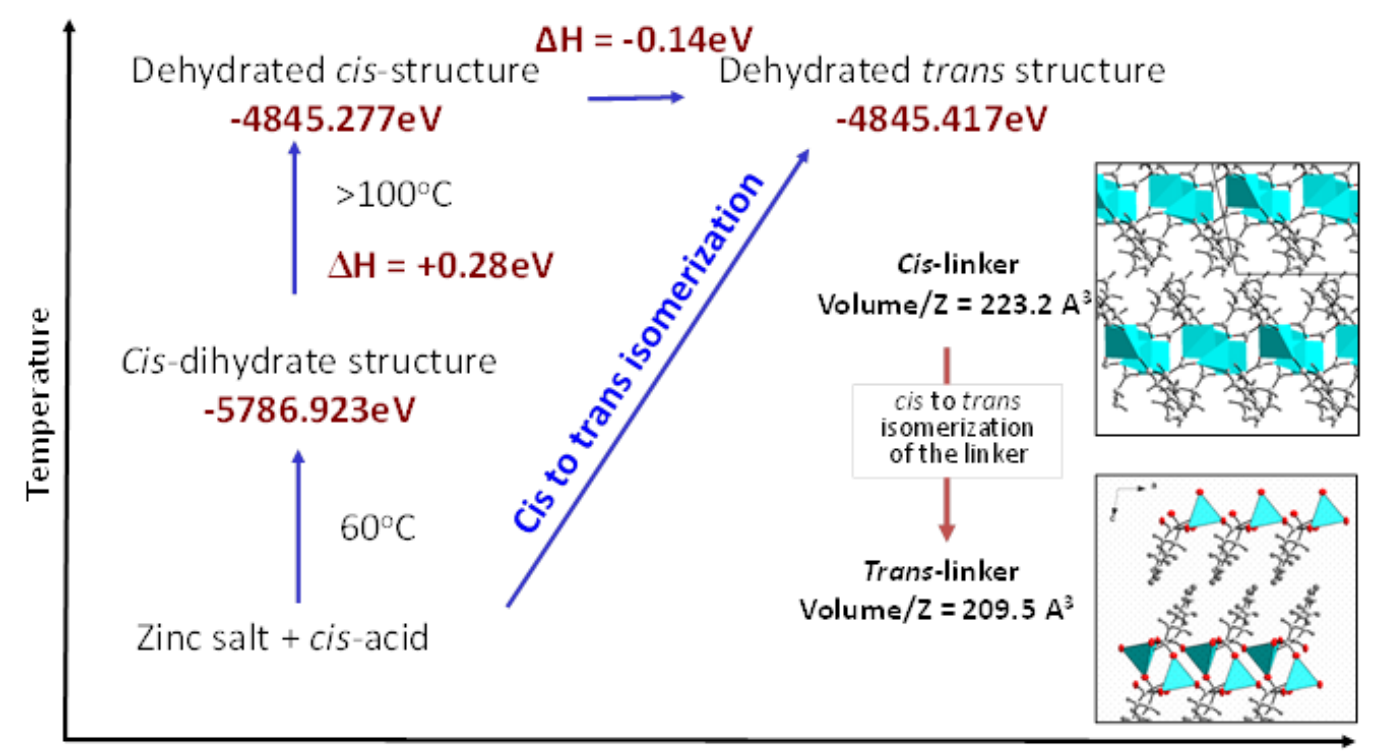

Time 
Figure 9

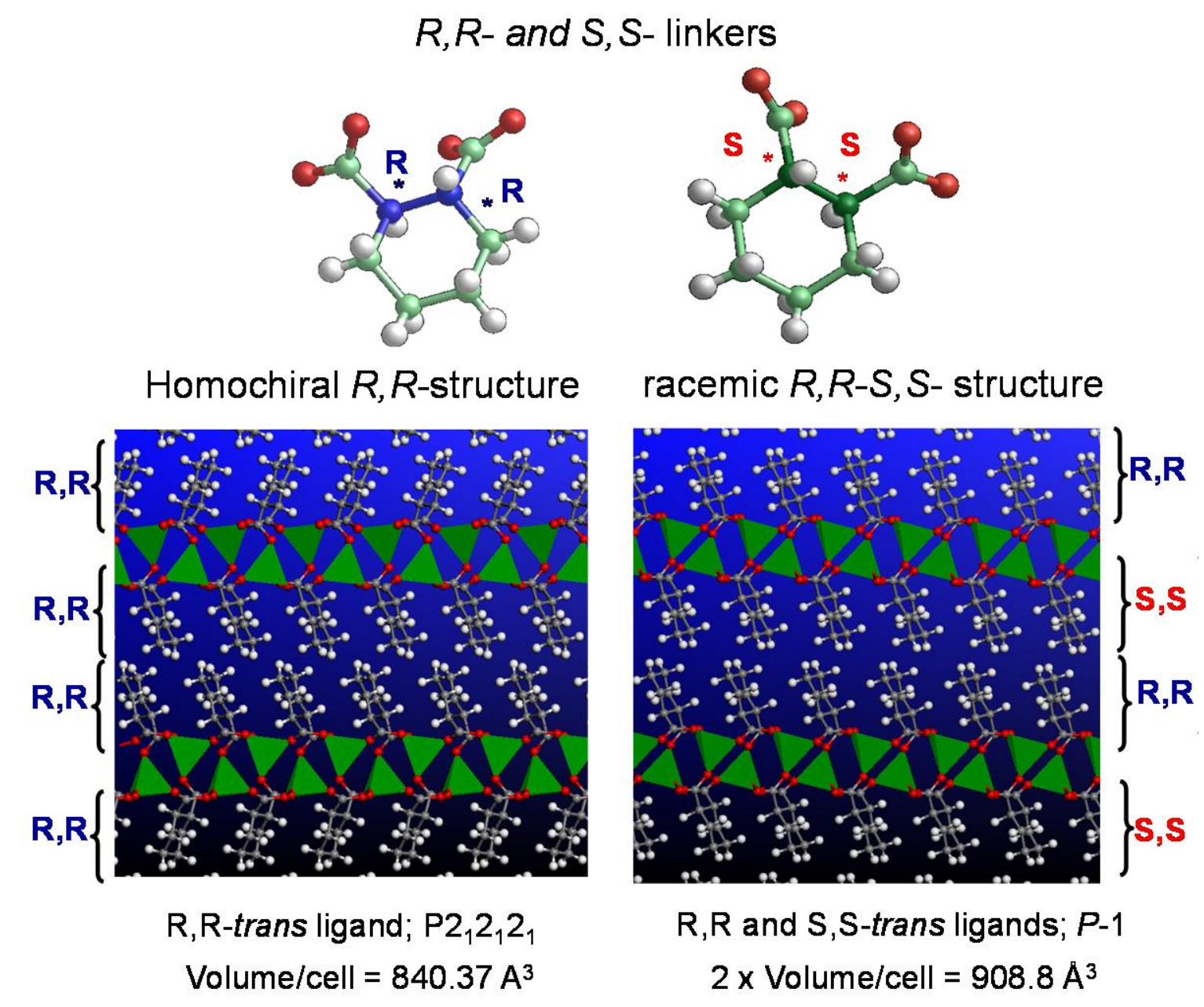


Figure 10

A
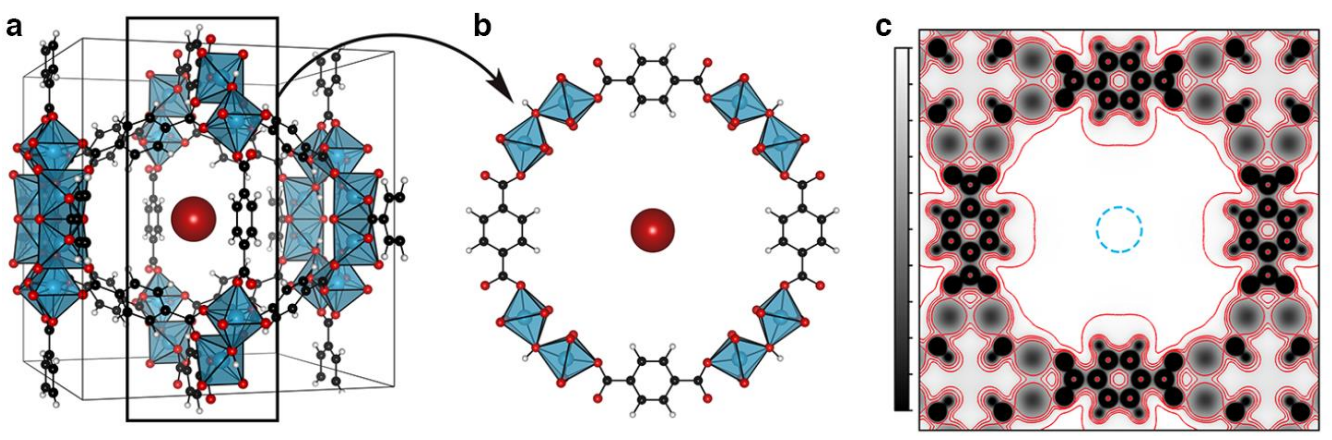

B

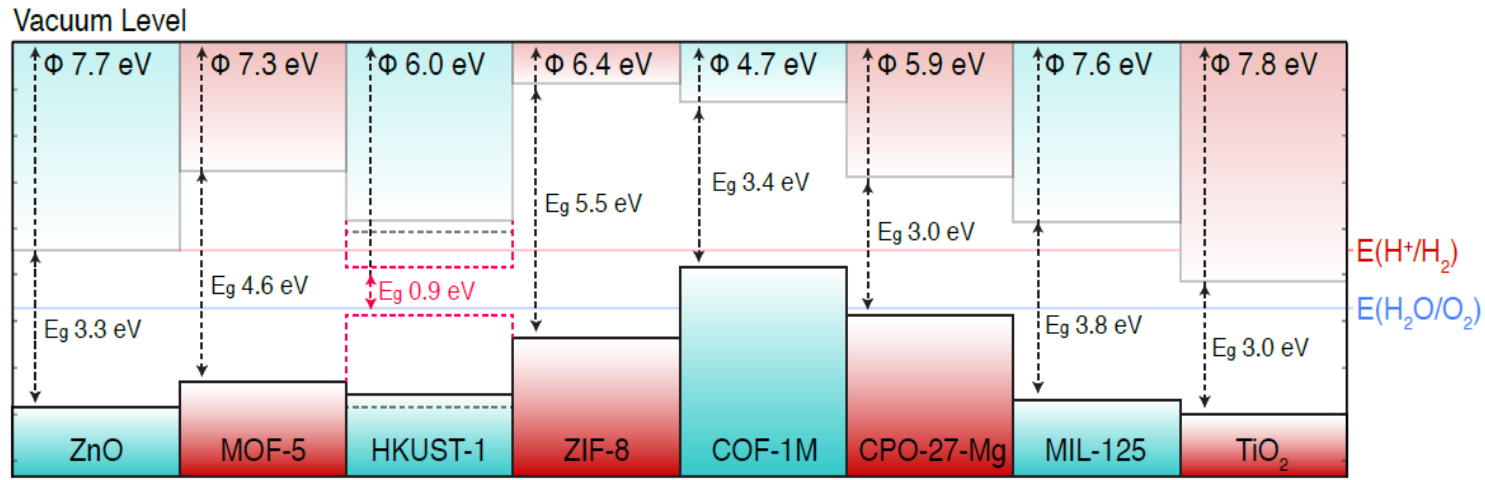

Valence Band 


\section{Figure 11}

A

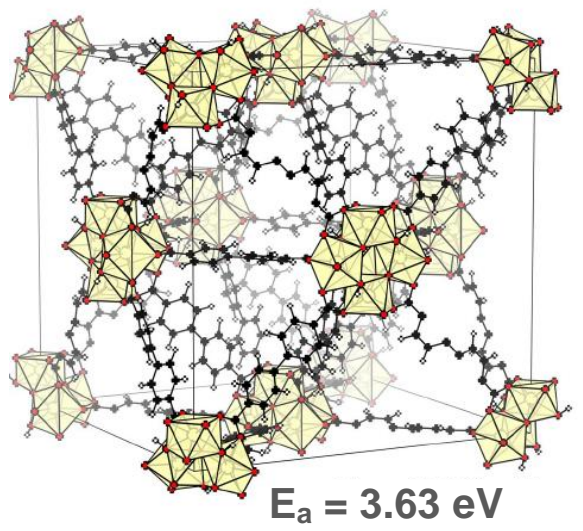

B

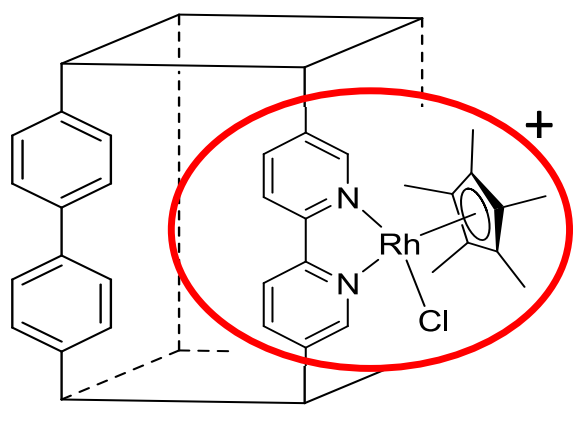

$E_{a}=2.34 \mathrm{eV}$

C

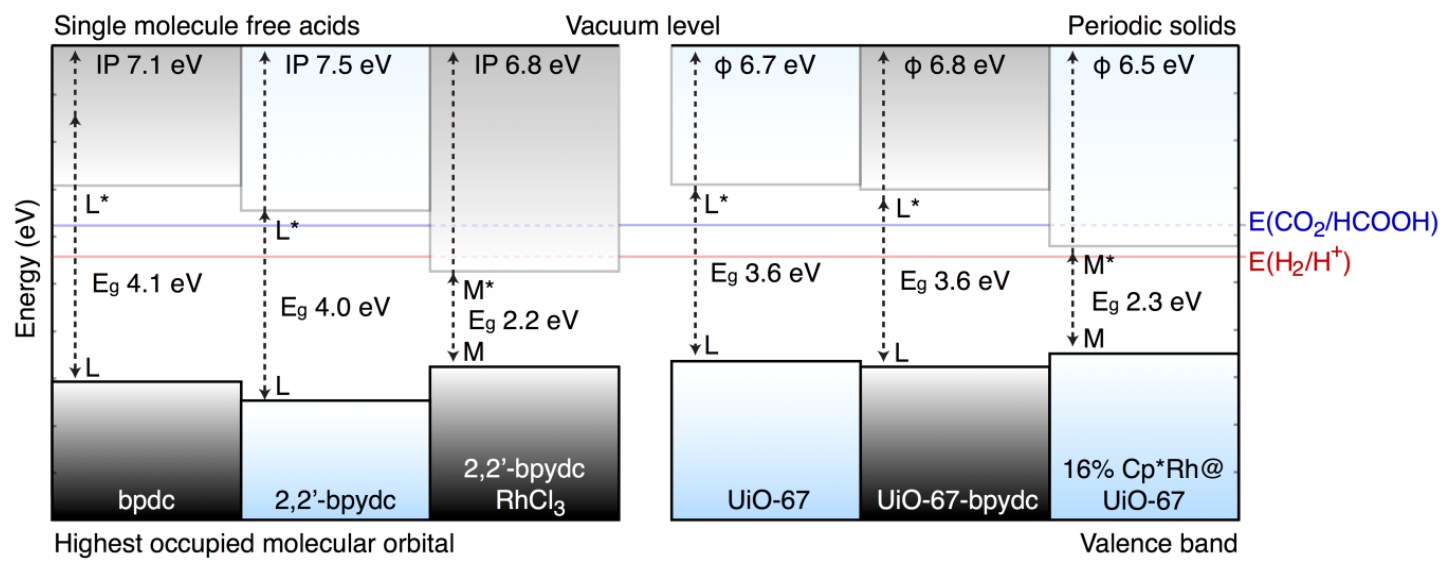


Figure 12

A<smiles>[R][R4]([R])([H])[O-]</smiles>

bdc- $\left(\mathrm{NH}_{2}\right)_{2}$<smiles>Nc1cc(C(=O)O)c(N)cc1C(=O)O</smiles>

$\mathrm{R}=\mathrm{H}, \mathrm{NH}_{2}, \mathrm{OH}, \mathrm{CH}_{3}, \mathrm{Cl}$

B

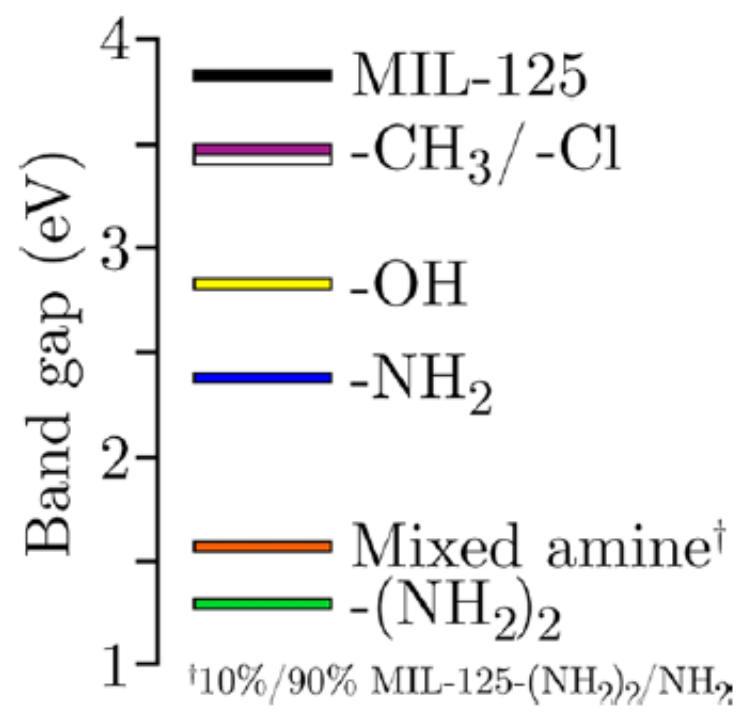

